\title{
Circular Supply Chain Management: A Definition and Structured Literature Review
}

(Citation: Farooque, M., Zhang, A., Thürer, M., Qu, T., Huisingh, D., 2019. Journal of Cleaner Production, 228, 882-900. https://doi.org/10.1016/j.jclepro.2019.04.303.)

Muhammad Farooque ${ }^{1,2}$ (muhammad.farooque@aut.ac.nz), Abraham Zhang*1,3

(abraham.zhang@aut.ac.nz), Matthias Thürer ${ }^{4}$ (matthiasthurer@workloadcontrol.com), Ting $\mathrm{Qu}^{4,5}$ (quting@jnu.edu.cn), Donald Huisingh ${ }^{6,7}$ (dhuisingh@utk.edu)

${ }^{1}$ Auckland University of Technology (AUT) Business School, AUT University, Private Bag 92006, Auckland 1142, New Zealand

${ }^{2}$ Sukkur IBA University, Sukkur, Pakistan.

${ }^{3}$ Lumen Research Institute, Excelsia College and Indiana Wesleyan University, 69-71 Waterloo Road, Macquarie Park, NSW 2113 Australia

${ }^{4}$ School of Intelligent Systems Science and Engineering, Jinan University (Zhuhai Campus), 519070, Zhuhai, PR China

${ }^{5}$ Institute of Physical Internet, Jinan University (Zhuhai Campus), 519070, Zhuhai, PR China ${ }^{6}$ Department of Engineering Management, POLITECNICO DI MILANO, Italy

${ }^{7}$ The Institute for a Secure and Sustainable Environment, University of Tennessee, Knoxville, USA

(*Corresponding author: abraham.zhang@aut.ac.nz) 


\title{
Circular Supply Chain Management: A Definition and Structured Literature Review
}

\begin{abstract}
Circular economy is increasingly recognized as a better alternative to the dominant linear (take, make, and dispose) economic model. Circular Supply Chain Management (CSCM), which integrates the philosophy of the circular economy into supply chain management, offers a new and compelling perspective to the supply chain sustainability domain. Consequently, there is increasing research interest. However, a review of the extant literature shows that a comprehensive integrated view of CSCM is still absent in the extant literature. This prohibits a clear distinction compared to other supply chain sustainability concepts and hinders further progress of the field. In response, this research first classifies various terminologies related to supply chain sustainability and conceptualizes a unifying definition of CSCM. Using this definition as a base, it then conducts a structured literature review of 261 research articles on the current state of CSCM research. Based on the review results, the researchers call for further studies in the following directions that are important but received little or no attention: design for circularity, procurement and CSCM, biodegradable packaging, circular supply chain collaboration and coordination, drivers and barriers of CSCM, circular consumption, product liabilities and producer's responsibility, and technologies and CSCM.
\end{abstract}

Keywords: supply chain management; circular economy; circular supply chain; circular supply chain management; sustainable supply chain; sustainability

Article Classification: Literature review 


\section{Introduction}

Sustainability has provoked a multitude of discussions and debates in the academic literature, including the Supply Chain Management (SCM) literature (Seuring and Müller, 2008; Morali and Searcy, 2013). However, global patterns of production, consumption, and trade still remain dangerously unsustainable (Preston, 2012). At its current level of consumption, the world will deplete many natural resources in the foreseeable future if there is no change in the way products are sourced, produced, delivered, used, reclaimed and regenerated (Hazen et al., 2017).

One important philosophy that may bring about this change is the circular economy (CE), a philosophy that has been increasingly recognized as a better alternative to the dominant linear (take, make, and dispose) economic model (Ghisellini et al., 2016). The CE philosophy is evolving into an influential driving force behind sustainability, both in the literature and in practice (Hobson, 2016; Stewart and Niero, 2018), and it has begun to be recognized as of great potential to help organizations achieve a breakthrough in sustainability performance.

CE was promoted by the Ellen MacArthur Foundation (EMF) (2014) as an industrial system that is restorative and regenerative by design. CE aims to keep products, components, and materials at their highest utility and value at all times in both biological and technical cycles. This means biological ingredients or nutrients can be safely returned to the biosphere and enhance natural capital. Similarly, geosphere-derived technical nutrients can be designed for recovery (remanufacturing, refurbishing, and recycling); thus, they can be kept within the technosphere by being circulating in and contributing to the economy with minimal wastages (EMF 2012; 2014). 
Integrating $\mathrm{CE}$ into SCM can provide advantages from a sustainability viewpoint (Genovese et al., 2017; Nasir et al., 2017). Consequently, there is enthusiasm and a growing interest in SCM for CE (Ying and Li-jun, 2012; Aminoff and Kettunen, 2016; Darom and Hishamuddin, 2016; Batista et al., 2018a; Batista et al., 2018b; Bressanelli et al., 2018b; De Angelis et al., 2018; Govindan and Hasanagic, 2018; Howard et al., 2018; Kazancoglu et al., 2018; Liu et al., 2018). However, SCM research is still at a nascent stage when it comes to conceptualizing how to advance supply chain theories and practices to help realize the vision and potential of a CE.

In the SCM literature on sustainability, a number of concepts, such as sustainable supply chains, green supply chains, environmental supply chains, and closed-loop supply chains, have been introduced and used interchangeably (Gurtu et al., 2015) to express the integration of sustainability concepts in SCM (Ahi and Searcy, 2015). While these concepts represent different degrees of integrating sustainable thinking into supply chains, none of them have systematically integrated circular thinking - i.e., the essence of the CE philosophy - into SCM. Some recent reviews on integrating CE into SCM have a rather narrow scope (Batista et al., 2018a; Govindan and Hasanagic, 2018). Meanwhile, the extant literature on CE and SCM sustainability remains fragmented where some key principles of $\mathrm{CE}$ are reflected at a strategic level and others around SCM functions such as design, procurement, production, etc.

While the term "circular supply chain" was used in some studies to link CE with SCM (Canning, 2006; Du et al., 2010; Genovese et al., 2017; Nasir et al., 2017; De Angelis et al., 2018; Mishra et al., 2018) it is only very recent that a working definition of circular supply chain management (CSCM) appeared in the literature. CSCM has been defined as: 
"the coordinated forward and reverse supply chains via purposeful business ecosystem integration for value creation from products/ services, by-products and useful waste flows through prolonged life cycles that improve the economic, social and environmental sustainability of organizations" (Batista et al., 2018a, p. 446).

Apparently, this closely mirrors the definition of sustainable supply chain management:

"the management of material, information and capital flows as well as cooperation among companies along the supply chain while taking goals from all three dimensions of sustainable development, i.e., economic, environmental and social, into account which are derived from customer and stakeholder requirements” (Seuring and Müller, 2008, p.1700).

It does not sufficiently reflect the two aspects that make a CSCM unique: 1) its restorative and regenerative cycles designed based on circular thinking; 2) the vision of a zero-waste economy that is inherent in the CE philosophy. Therefore, this definition is likely to lead to confusion with existing sustainability concepts in the context of SCM and consequently may hinder the development of CSCM. In response, the current study aims to achieve the following objectives:

1. To conceptualize a new definition of CSCM;

2. To map the current state of research on all the aspects and facets of CSCM by use of a structured review of literature; and,

3. To identify important directions for future research in CSCM.

The remainder of this paper is organized as follows: section 2 classifies the supply chain sustainability concepts and defines CSCM. Section 3 then describes how the structured 
literature review on CSCM has been conducted, and section 4 then presents the results of our review. Section 5 discusses important future research directions that emerged from the review. Finally, section 6 concludes this study.

\section{Supply Chain Sustainability Terms and CSCM}

To the best of our knowledge, this is one of the early attempts to conceptualize and define a comprehensive integrated view of CSCM, to appropriately distinguish it from other sustainability concepts presented in the supply chain literature. To do so, this section first classifies existing supply chain sustainability concepts and discusses its relation to the $\mathrm{CE}$ philosophy in Section 2.1. Section 2.2 then presents a working definition for CSCM.

\subsection{Classification of Supply Chain Sustainability Terms}

Sustainability concepts in the SCM literature have been largely inspired by Elkington's (2004) idea of a triple bottom line (TBL) which suggest that organizational sustainability consists of three components: the natural environment, society, and economic performance at a broader level (Carter and Dale, 2008). Based on these three components different terminologies emerged from the literature, for example, "sustainable supply chain management" (Seuring and Müller, 2008; Craig and Easton, 2011; Anne and Helen, 2015; Leszczynska and Maryniak, 2017), "green supply chains" (Srivastava, 2007; Chakraborty, 2010; Seman et al., 2012; Malviya and Ravi, 2015), "closed loop supply chains" (Souza, 2013; Govindan et al., 2015), and "environmental supply chains" (Darom and Hishamuddin, 2016). Each of these concepts gave different weight to the three components. For example, Ahi and Searcy (2013) performed a comparative analysis of 12 unique definitions of sustainable supply chain management (SSCM) from 56 articles and 22 unique definitions of green supply chain management (GSCM) from 124 articles. They found that most definitions for SSCM explicitly addressed all three 
dimensions of the TBL. In contrast, none of the published definitions on GSCM explicitly mentioned social issues.

EMF (2017) defined the CE philosophy as "Looking beyond the current take, make and dispose extractive industrial model, the circular economy is restorative and regenerative by design. Relying on system-wide innovation, it aims to redefine products and services to design waste out, while minimizing negative impacts. Underpinned by a transition to renewable energy sources, the circular model builds economic, natural and social capital". The CE philosophy makes a clear distinction between products' biological (regenerative) and technical (restorative) cycles. The biological materials or nutrients become part of the biosphere as natural capital and can be reused as production inputs, whereas the technical materials or nutrients (polymers, alloys and other man-made compounds) are designed for material recovery through repair, refurbishing, remanufacturing, and recycling (Weetman, 2017). Thus, CE may, if actualized, operate in ways where product design, usage, and re-usage based economic activities mimic the natural ecosystem; i.e., natural resources transformed into manufactured products and the manufactured by-products are used as resources for other industries (Zhu et al., 2010).

Integrating $\mathrm{CE}$ in SCM would begin to extend the boundary of SSCM and GSCM by reducing the need of virgin materials which could increase the circulation of resources within supply chains systems (Andersen, 2007; Genovese et al., 2017). However, based on our analysis of the literature on $\mathrm{CE}$, there is a knowledge gap in terms of how to integrate $\mathrm{CE}$ into SCM (see also Aminoff and Kettunen (2016)). As presented in Table 1, the sustainability discussion in SCM has mainly addressed restoration options (repair, refurbishing, remanufacturing and recycling) while the regeneration concept has not been discussed in the 
SCM sustainability context. So, there is a need to enhance the existing sustainability concepts in SCM towards a CSCM.

Table 1: Sustainability in SCM and CE

\begin{tabular}{|c|c|c|c|c|c|c|}
\hline \multirow{2}{*}{$\begin{array}{c}\text { Sustainability in SCM } \\
\text { (Terms) }\end{array}$} & \multirow[b]{2}{*}{ Definition Source } & \multicolumn{3}{|c|}{ Sustainability Dimension } & \multicolumn{2}{|c|}{ Integration of CE } \\
\hline & & Environmental & Economic & Social & Restorative* & Regenerative* \\
\hline $\begin{array}{c}\text { Sustainable Supply Chain } \\
\text { Management }\end{array}$ & $\begin{array}{l}\text { Seuring and Müller } \\
\text { (2008) }\end{array}$ & घ & घ & घ & घ & \\
\hline $\begin{array}{c}\text { Green Supply Chain } \\
\text { Management }\end{array}$ & Srivastava (2007) & घ & घ & & घ & \\
\hline $\begin{array}{c}\text { Environmental Supply Chain } \\
\text { Management }\end{array}$ & $\begin{array}{l}\text { Zsidisin and Siferd } \\
\qquad(2001)\end{array}$ & घ & घ & & च & \\
\hline Closed Loop Supply Chains & $\begin{array}{c}\text { Guide and Van } \\
\text { Wassenhove (2006) }\end{array}$ & - & घ & & - & \\
\hline
\end{tabular}

* Restorative: Ability of end of life products/materials to become technical nutrients through repair, refurbishing, remanufacturing, and recycling (Ellen MacArthur Foundation (EMF), 2017)

* Regenerative: Ability of end of life products/materials to become biological nutrients and become part of the biosphere as natural capital for reuse (Ellen MacArthur Foundation (EMF), 2017)

\subsection{Circular Supply Chain Management Definition}

The integration of CE into SCM has been termed circular supply chain in the literature (Canning, 2006; Du et al., 2010; Genovese et al., 2017; Nasir et al., 2017). However, there is no comprehensive definition of CSCM. Therefore, we proposed the following definition:

Circular supply chain management is the integration of circular thinking into the management of the supply chain and its surrounding industrial and natural ecosystems. It systematically restores technical materials and regenerates biological materials toward a zero-waste vision through system-wide innovation in business models and supply chain functions from product/service design to end-of-life and waste 
management, involving all stakeholders in a product/service lifecycle including parts/product manufacturers, service providers, consumers, and users.

CSCM significantly enhances SSCM and GSCM by a regenerative dimension. It advances sustainability thinking by systematically applying CE's circular thinking in all supply chain stages and functions. As with the CE philosophy, CSCM is applicable to manufactured products as well as to service products. In CSCM, organizations collaborate with others within and outside of the sector to maximize the utility of goods/materials. It offers a promising vision to guide supply chain managers to achieve a breakthrough performance in resource efficiency, and consequently, profitability. Simultaneously, it minimizes the negative environmental, social, and economic impacts.

The purpose of CSCM is to lead towards circular supply chains as illustrated in Figure 1. Figure 1 contrasts a circular supply chain (Figure 1c) with a traditional (linear) supply chain (Figure 1a) and a closed loop supply chain (Figure 1b). A linear supply chain extracts resources from the geosphere and the biosphere and disposes off EoL products, packaging materials, and wastes from multiple supply chain stages. The unwanted items are often deposited in landfills. A closed loop supply chain improves environmental performance by bringing back goods and packaging materials to the producer to recover value (Guide and Van Wassenhove, 2006). For example, closed loop remanufacturing of photocopiers can conserve $20-70 \%$ of materials, labor, and energy and reduce waste by $35-50 \%$ as compared to conventional manufacturing (Toffel, 2004). However, the extent of value recovery in a closed loop supply chain is often limited because the efforts are restricted within the original supply chain (producer's supply chain) and do not include secondary supply chains and/or involve new auxiliary channel members (Moula et al., 2017). A closed loop supply chain still generates substantial amounts 
of waste as it is rarely feasible to reuse/recycle all unwanted items within the same supply chain. A circular supply chain goes further by recovering value from waste by collaborating with other organizations within the industrial sector (open loop, same sector), or with different industrial sectors (open loop, cross-sector) (Weetman, 2017).

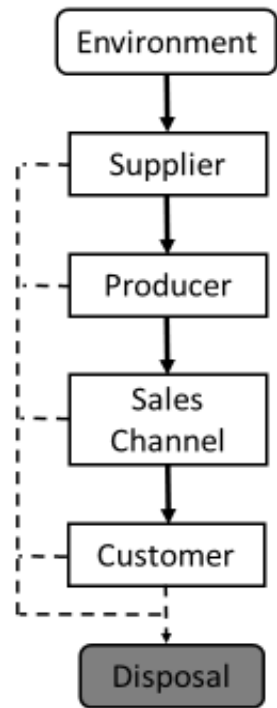

A) Linear supply chain

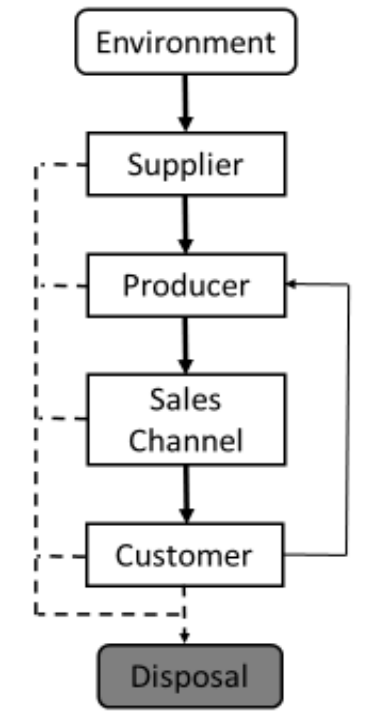

B) Closed loop supply chain

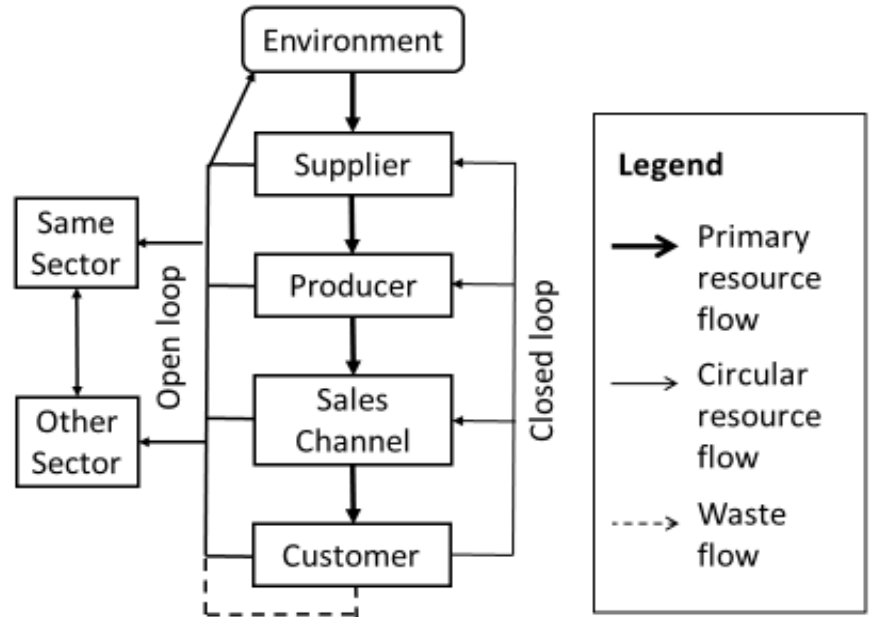

Toward

zero waste

C) Circular supply chain

Figure 1. Linear, closed loop and circular supply chains

Ideally, a circular supply chain will generate zero waste because it is designed to systematically restore and regenerate resources in the industrial and natural ecosystem in which it is embedded. Circular supply chains have two types of resource flows: primary resource flows and circular resource flows, as illustrated in Figure 1c. The primary resource flows are identified with the forward flow of goods in the linear and closed-loop supply chains. The circular resource flows represent the "re-" type flows of goods/materials/energy that are recycled, retained, reused, repaired, remanufactured, refurbished, recovered, etc. 
In practice, CSCM endeavor to produce zero waste through system-wide innovations to recover value from what was traditionally called "waste". For example, recycled PET bottles may be used for construction; light concrete is added to the bottles, creating isolated walls for houses (Scheel and Vazquez, 2011; Scheel and Vasquez, 2013). Similarly, a manufacturer may recycle textile materials to produce insulation products for the construction industry (Nasir et al., 2017) while a food supply chain's waste cooking oil may be refined and utilized to produce biodiesel (Genovese et al., 2017). Food wastes can be minimized at their sources and the remaining food wastes can be composted or anaerobically digested to produce methane as a renewable energy source and fermentate, which can be used as a fertilizer in agriculture/horticulture.

Based on the CSCM conceptualization presented above, we have developed one of the earlier literature reviews in this emerging field. We hope that this significantly furthers the development of CSCM and provides a new dimension for sustainability researchers in SCM, offering significant managerial, policy, human health, and eco-system health implications.

\section{Methodology}

A structured review of the literature was conducted to summarize the current state of academic research on CSCM. A procedure similar to Seuring and Müller (2008); Harland et al. (2006) and Mayring (2003) was used for retrieving and selecting the articles. The following subsections outline the approach adopted for sourcing, screening, analyzing the articles and sample characteristics. 


\subsection{Sourcing the Articles}

There are, arguably, three major abstract and citation databases: Google Scholar, Scopus, and the Web of Science. We excluded Google Scholar because of its low data quality, which raises questions about its suitability for research (Meho and Yang, 2007; Mongeon and Paul-Hus, 2016). Meanwhile, Scopus has a broader coverage than the Web of Science, but the latter provides access to older sources. Since we are investigating a recent phenomenon, the access to older sources offered by the Web of Science database is not an advantage. We, therefore, focused on Scopus. In general, the number of journals in the Web of Science not covered by Scopus is about $5 \%$, and the number of Scopus articles not covered by the Web of Science is about 50\% (Mongeon and Paul-Hus, 2016). Meanwhile, we did not use a full-text database (such as EBSCO, Elsevier, ProQuest, Sage, Springer, Taylor \& Francis, or Wilson) in a bid to avoid excluding any particular publisher from the search. All articles published until 2018 were considered.

To maintain the quality of content and to keep the selected articles to a manageable number, the search was restricted to "Articles", "Articles in press" and "Review articles" published in peer-reviewed journals. Although representing a limitation, only English sources were included in our review given the language limitations of the author team. Scopus was queried using the keywords summarized in Table 2. This step retrieved 2987 publications. After removing duplicates, 1748 articles remained.

\subsection{Screening the Articles}

At the screening stage, articles were included/excluded based on the abstract, which was retrieved from the database. All abstracts of the original sample of 1748 articles were read. Any 
article that covered aspects of CE in a SCM context were retained. Most of the analysis was executed by two researchers/authors. The abstracts were read by both researchers independently and the results were compared. Any inconsistencies of interpretation were resolved through discussion until consensus was reached. All articles for which no clear decision could be reached were put in a backlog. The backlog was then cleared by both researchers through in-depth discussion, with a bias towards including the article if there was any doubt. This rather subjective procedure based on the judgement was required since the literature on CSCM is very broad and covers many different areas. Hence, no specific inclusion/exclusion criteria could be applied beyond whether or not a paper appeared to be incorporating a focus on CE in a SCM context at the micro level (firm or supply chain level).

The screening reduced the relevant articles to 270 . The high number of unrelated articles is justified seen our broad search terms which included many articles that did not explicitly integrate the CE philosophy into SCM (i.e., with an exclusive focus on CE or supply chain sustainability). Focusing on articles that explicitly focus on the integration of CE into SCM differentiates our literature review work from reviews in SSCM (Seuring and Müller, 2008; Ansari and Kant, 2017; Dubey et al., 2017a), GSCM (Srivastava, 2007; Fahimnia et al., 2015; Malviya and Ravi, 2015), closed loop supply chain (Souza, 2013; Govindan et al., 2015; Govindan and Soleimani, 2017) and CE (Su et al., 2013; Ghisellini et al., 2016; Lieder and Rashid, 2016). Using several channels for retrieving the full articles, i.e., database subscription/access available to the authors, a total of 261 articles were obtained and evaluated as the final sample. Figure 2 summarizes the structured literature review process. 
Table 2: Keywords used for search and number of papers retrieved

\begin{tabular}{|c|c|c|}
\hline \multicolumn{3}{|c|}{ 1st step } \\
\hline No. & Keywords used for search & $\begin{array}{c}\text { Papers } \\
\text { retrieved }\end{array}$ \\
\hline 1 & Circular economy AND supply chain & 152 \\
\hline 2 & Circular economy AND value chain & 59 \\
\hline 3 & Circular economy AND operations management & 5 \\
\hline 4 & Circular economy AND sustainable supply chain & 16 \\
\hline 5 & Circular economy AND green supply chain & 14 \\
\hline 6 & Circular economy AND closed loop supply chain & 22 \\
\hline 7 & Circular economy AND environmental supply chain & 1 \\
\hline 8 & Circular economy AND reverse logistics & 25 \\
\hline 9 & Circular economy AND logistics & 47 \\
\hline 10 & Circular economy AND design & 297 \\
\hline 11 & Circular economy AND procurement & 15 \\
\hline 12 & Circular economy AND manufacturing & 175 \\
\hline 13 & Circular economy AND production & 611 \\
\hline 14 & Circular economy AND end of life & 116 \\
\hline 15 & Circular economy AND remanufacturing & 68 \\
\hline 16 & Circular economy AND refurbish & 20 \\
\hline 17 & Circular economy AND repair & 25 \\
\hline 18 & Circular economy AND reuse & 222 \\
\hline 19 & Circular economy AND recycle & 64 \\
\hline 20 & Circular economy AND reduce & 204 \\
\hline 21 & Circular economy AND restore & 5 \\
\hline 22 & Circular economy AND regenerate & 7 \\
\hline 24 & Circular economy AND consumption & 292 \\
\hline 25 & Circular economy AND product service systems & 33 \\
\hline 26 & Circular economy AND PSS & 16 \\
\hline 27 & Circular economy AND business model & 137 \\
\hline 28 & Circular economy AND waste management & 339 \\
\hline \multicolumn{2}{|r|}{ Total number of papers retrieved } & 2987 \\
\hline \multicolumn{3}{|c|}{ 2nd step } \\
\hline 1 & Circular economy & 1748 \\
\hline
\end{tabular}



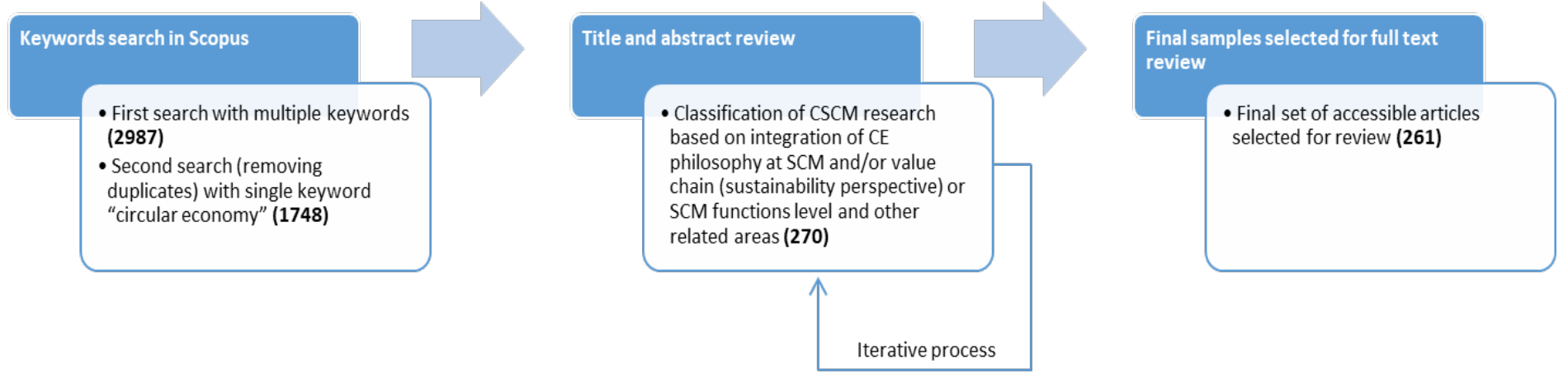

Figure 2: Structured literature review process

\subsection{Analyzing the Articles}

This stage involved extracting and documenting information from the 261 articles. To minimize subjectivity, the authors: (i) cross-checked results; and, (ii) conducted regular meetings among themselves to resolve any emerging inconsistencies in interpreting the results. Our major research vehicle was content analysis (see, Krippendorff (2004)). To ensure that we did not miss relevant information, we held regular meetings to discuss issues and to clarify ambiguities. As a template for data collection, a simple matrix was used where, for each paper (row), we asked (column) the following questions:

- What part(s) of CE were integrated into SCM or value chain (from a sustainability viewpoint)?

- What part(s) of CE were integrated into SCM functions?

- Which circular business models were discussed in the publication?

- What role did technology play in integrating CE in SCM?

- Which industrial sector did it focus upon?

- Which country was the context of the research?

- What was the research/analysis methodology? 
- What were the key findings, lessons, recommendations for the short and long-term future?

Before presenting the results, Section 3.4 summarizes the basic sample characteristics.

\subsection{Sample Characteristics}

The distributions of publications by the year of publication are presented in Figure 3. The discussion of CE elements in supply chain sustainability literature started in the late 2000 s and continued at a modest rate until 2015. There has been an increase of papers on this topic since the beginning in 2016, which indicates a growing research interest in this field, further supporting the need for our comprehensive review (see Figure 3).

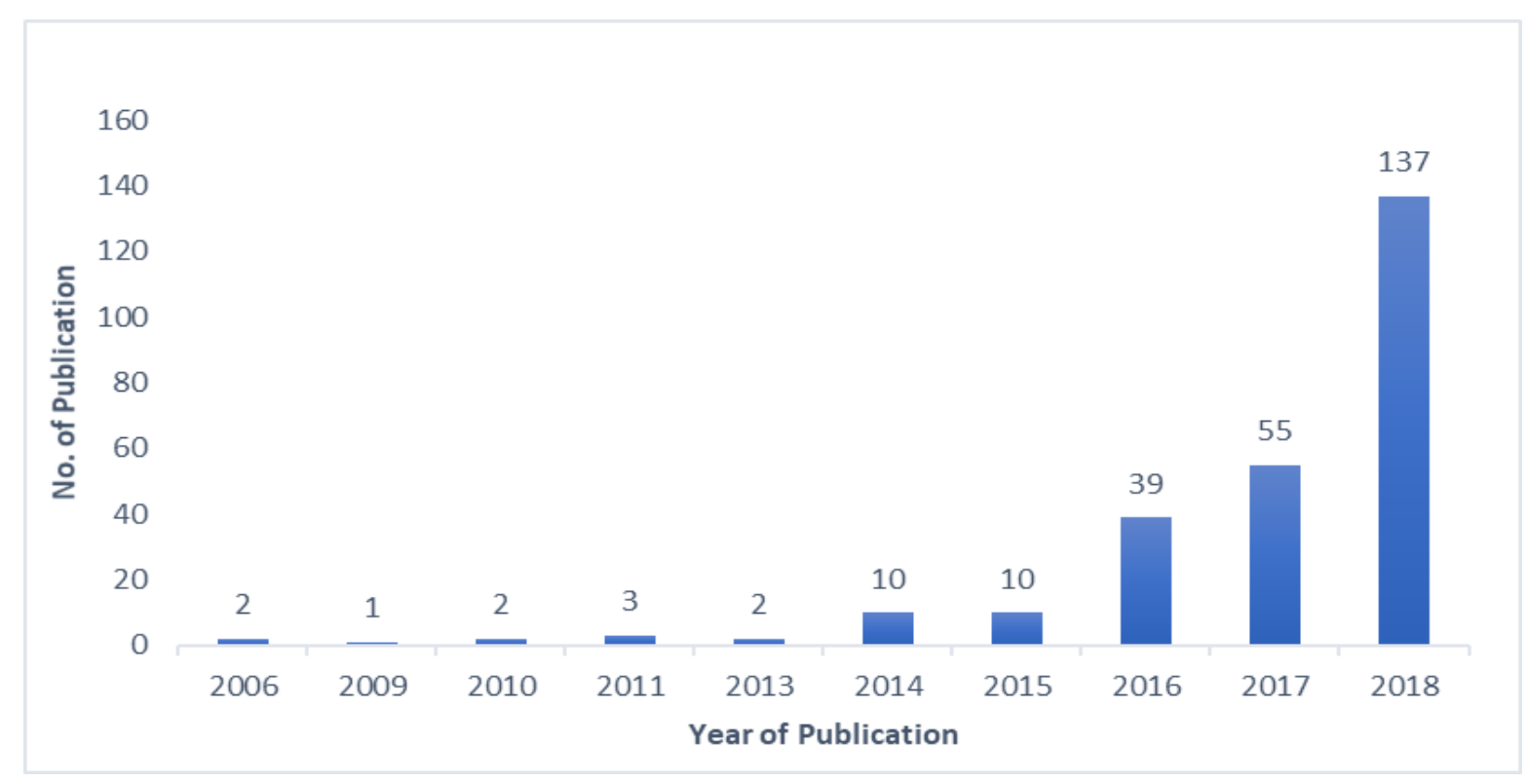

Figure 3. Distribution of articles per year

Table 3 presents the distribution of journals across which the articles were published. The sample contains articles from a broad set of journals. It was found that 51 journals have published just one paper on the topic. Moreover, as anticipated, the leading journals in the field 
head the list with the highest contribution of relevant articles in the Journal of Cleaner Production (64) in the emerging field of CSCM research.

Meanwhile, Figure 4 presents the distribution of the research context by countries. The results indicate a leading role of China in accelerating CSCM research. Moreover, substantial research in the CSCM has also been conducted in the United Kingdom (UK), The Netherlands, United States of America (USA), and Sweden including other European countries. The European Union's (EU) growing interest in CSCM is evident in Figure 4. However, these statistics exclude the publications where the research context was unclear or unspecified.

Table 3: Distribution of reviewed articles by journal

\begin{tabular}{lcc}
\hline Journal Name & No. of papers & \% \\
\hline Journal of Cleaner Production & 63 & 24.14 \\
Sustainability (Switzerland) & 32 & 12.26 \\
Resources, Conservation and Recycling & 26 & 9.96 \\
Journal of Industrial Ecology & 12 & 4.60 \\
International Journal of Production Research & 10 & 3.83 \\
Production Planning and Control & 10 & 3.83 \\
Waste Management & 7 & 2.68 \\
Business Strategy and the Environment & 7 & 2.68 \\
California Management Review & 5 & 1.92 \\
Resources & 5 & 1.92 \\
Management Decision & 5 & 1.92 \\
Environmental Innovation and Societal Transitions & 4 & 1.53 \\
Thunderbird International Business Review & 4 & 1.53 \\
Journal of Remanufacturing & 3 & 1.15 \\
Procedia Manufacturing & 3 & 1.15 \\
Journal of Manufacturing Technology Management & 3 & 1.15 \\
International Journal of Production Economics & 2 & 0.77 \\
Waste Management and Research & 2 & 0.77 \\
Journal of Environmental Management & 2 & 0.77 \\
CIRP Journal of Manufacturing Science and Technology & 2 & 0.77 \\
Technological Forecasting and Social Change & 2 & 0.77 \\
Science of the Total Environment & 2 & 0.77 \\
Others & 50 & 19.16 \\
\hline Total & $\mathbf{2 6 1}$ & $\mathbf{1 0 0 \%}$ \\
\hline
\end{tabular}




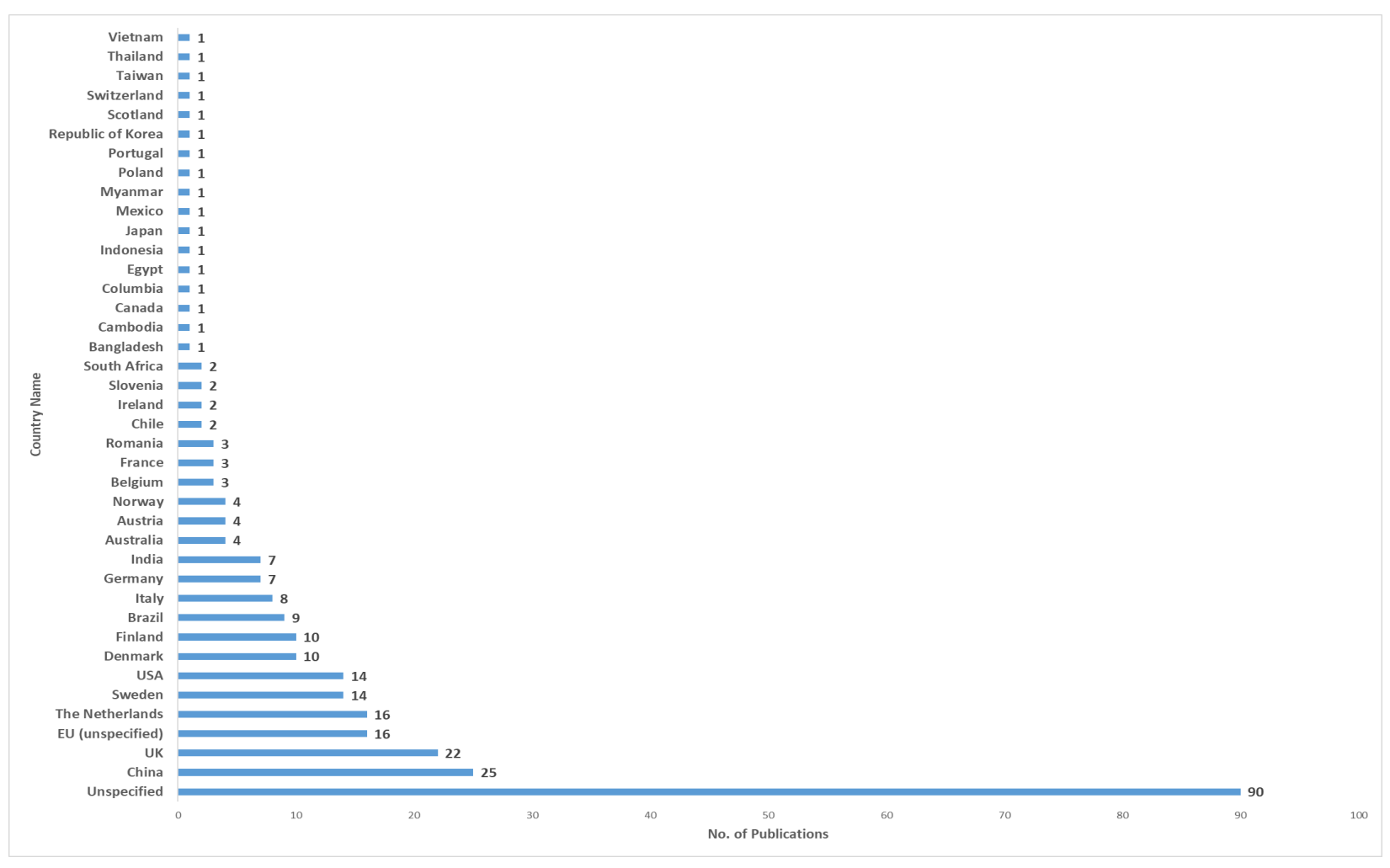

Figure 4. Distribution of reviewed articles by country

Figure 5 presents the distribution of articles by industrial sector. The International Standard Industrial Classification (ISIC), a United Nations system for classifying economic data, was used for classification purposes following Gao et al. (2017). The results indicate that the manufacturing sector (including publications where multiple manufacturing industries were indicated) has been the primary research field along with waste management and remediation activities for the relevant papers for this literature review. Wholesale and retail also play an active role in CSCM. Note that these statistics excluded many publications that did not specify any industrial sector. 


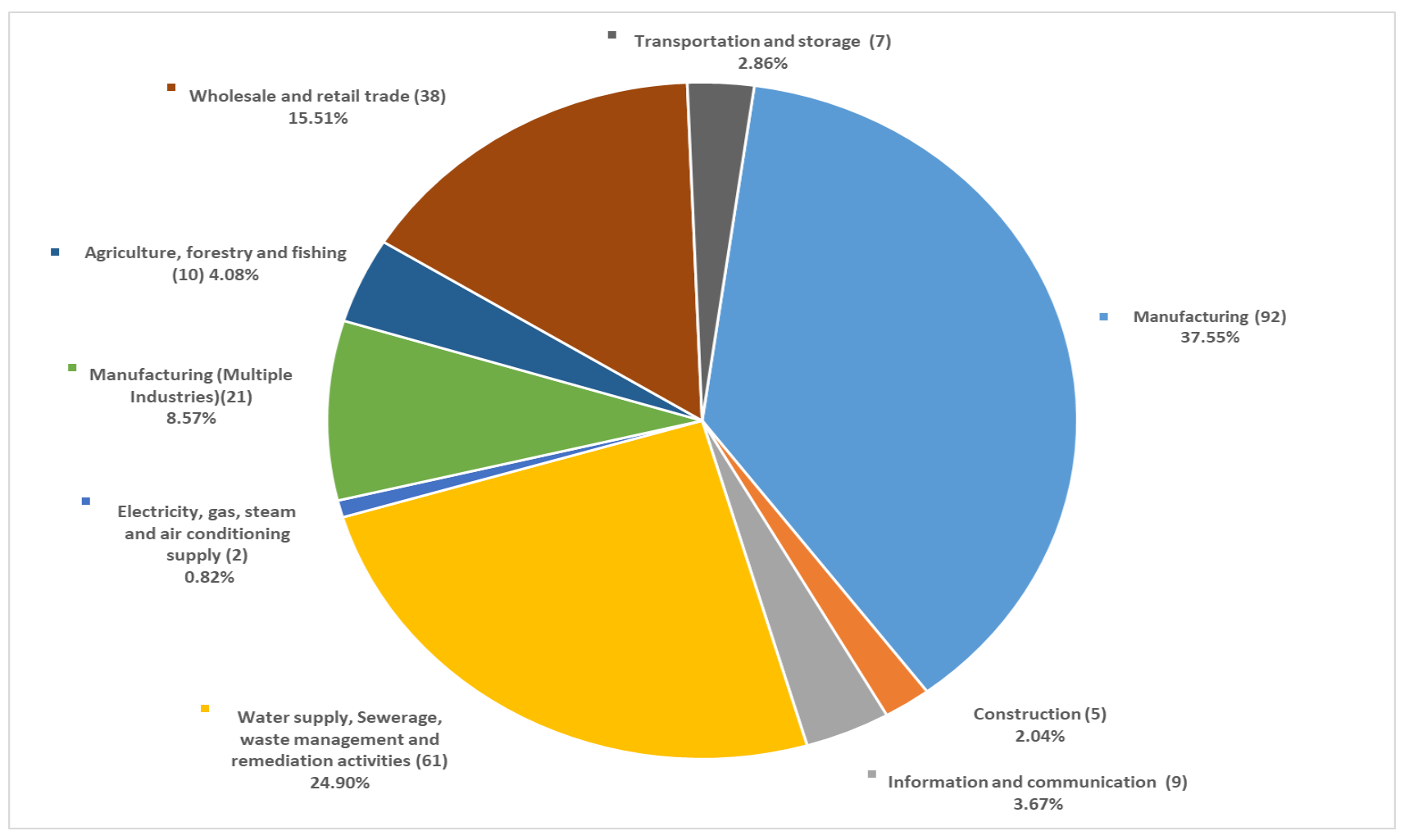

Figure 5. Distribution of reviewed articles by industry

Table 4 summarizes the frequency of research methods after analyzing the articles in detail. Empirical research (148) shows that research in the field of CSCM has mostly been driven by direct observation (case studies, surveys, etc.). Case study (110 papers) has been the most common methodology employed in the studies. Given that CSCM research is still in the early stage of development, it is of no surprise to see a large number of case studies conducted to identify the critical issues and to develop a clearer understanding of the topics. Conceptual/Theoretical model (43 papers) and Literature review (38) are the second and third most frequently used methods in different studies, respectively. These papers serve as the foundation to synthesize the existing knowledge and to develop important guidelines for future research in CSCM. Articles where quantitative approaches (Modeling) have been used for decision-making contribute to 19 papers. Other methods include experimental studies (7), and in a few cases, the researchers used a combination of different methods. 
Table 4: Distribution of reviewed articles based on research method

\begin{tabular}{lcc}
\hline Research Method & No. of papers & \% \\
\hline Empirical & 148 & $56.70 \%$ \\
$\quad$ - Case study (110) & & \\
- Survey (26) & & \\
- Interview (10) & & \\
- Mixed method (2) & & \\
- Others (2) & 43 & $16.48 \%$ \\
Conceptual/Theoretical & 38 & $14.56 \%$ \\
Literature review & 19 & $7.28 \%$ \\
Modelling & & \\
$\quad$ - Simulation (6) & & \\
$\quad$ - Optimization (9) & & \\
$\quad$ - Others (4) & 7 & $2.68 \%$ \\
Experimental & 4 & $1.53 \%$ \\
Literature review + Case study & 2 & $0.77 \%$ \\
Literature review + Interview + Case study & $\mathbf{2 6 1}$ & $\mathbf{1 0 0 \%}$ \\
\hline Total & & \\
\hline
\end{tabular}

\section{Review Results:}

Overall, the CSCM research is classified in two broad categories. The first category classifies the integration of CE philosophy at a broad SCM and/or value chain (sustainability perspective) level. This classification category includes 60 papers representing approximately $30 \%$ of the total papers reviewed. The second major category classifies the extant literature concerning the integration of CE philosophy at SCM functional level. A total of 121 papers across various functional areas included in this category represents nearly $46 \%$ of the reviewed article. Moreover, the business model and the role of technology represent the other two subcategories of CSCM classification. These subcategories include 67 and 13 papers, representing $26 \%$ and $5 \%$ of the reviewed papers respectively. Figure 6 presents the classification of CSCM research. 


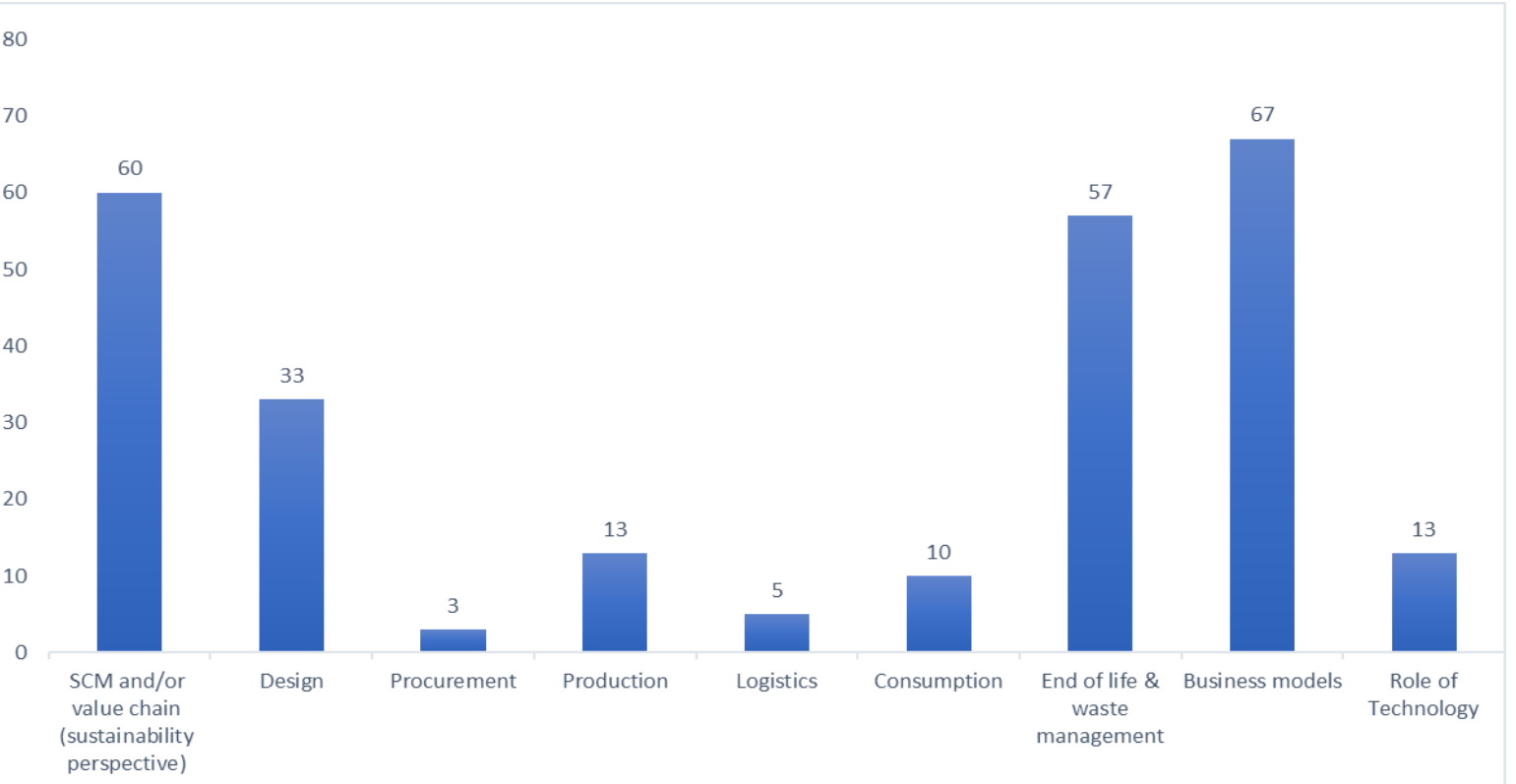

Figure 6. Classification of CSCM research

CSCM classification as presented in Figure 6 has been used to structure the remainder of this section. Note that the most relevant category was chosen when a publication was relevant to more than one category.

\subsection{Supply chain-wide integration of $\mathrm{CE}$}

\subsubsection{Supply chain management/value chain (Sustainability perspective)}

A recent review paper (Masi et al., 2017) clustered the circular supply chain research into three supply chain configurations: Eco-industrial parks (EIPs), environmental, sustainable, green systems, and closed-loop supply chains. While EIPs refer to a meso level CE implementation, (which is beyond the scope of this paper) the other two clusters represent the SCM sustainability domain, which is currently active in CSCM research. Recent examples include De Angelis et al. (2018) who explored the implications for SCM in circular supply chains comparing it with the traditional and sustainable supply chain. Batista et al. (2018a) contributed to the understanding of supply chain circularity (i.e., restorative and regenerative processes of 
CE). Winkler and Kaluza (2006) highlighted the importance of establishing Sustainable Supply Chain Networks to implement an integrated waste management system to achieve sustainable economic growth. Adopting an SSCM approach was considered to be helpful for organizations to create a blended business and environmental value, thus providing the impetus for organizations to adopt CE (Park et al., 2010). While others consider the integration of CE and CLSC as 'circular supply chains' (Lapko et al., 2018; Mishra et al., 2018). Circular and CLSCs focus more on value recovery operations through reverse logistics (Bernon et al., 2018; Larsen et al., 2018). GSCM and CE are also considered as concepts overlapping and supporting each other (Liu et al., 2018). In order to integrate the CE concept into GSCM, Kazancoglu et al. (2018) proposed a new holistic conceptual GSCM performance assessment framework integrating environmental, economic, logistics, operational, organizational and marketing performance.

\subsubsection{Drivers and barriers}

A number of studies have identified drivers (Bressanelli et al., 2018a; Govindan and Hasanagic, 2018; Huybrechts et al., 2018; Mangla et al., 2018; Ranta et al., 2018) and barriers (Govindan and Hasanagic, 2018; Mangla et al., 2018; Masi et al., 2018; Milios et al., 2018; Ranta et al., 2018) to CSCM development and implementation. However, it is important to note that drivers and barriers significantly vary by geographic and industrial contexts. This needs to be further explored for a widespread implementation of CSCM across the globe.

\subsubsection{Indicators and measurement tools}

Howard et al. (2018) argued that the abundance of CE indicators (typically fragmented and disjointed), make it difficult for firms to monitor, report and communicate progress towards the implementation of CE. Therefore, they proposed a new framework for the development of CE indicators which link to the core goals, principles and concepts of a CE. With regards to 
CSCM, Jain et al. (2018) developed a strategic framework for measuring CSCM using the supply chain operations reference (SCOR) model, but they primarily focused on the environmental dimension and not the social and economic dimensions.

Linder et al. (2017) proposed a novel circularity metric based on the ratio of recirculated economic value to total product value, using value chain costs as an estimator. This metric can enable producers and customers to quantify product-level circularity and contribute towards the transition to more sustainable CE. Di Maio et al. (2017) introduced 'value-based resource efficiency' (VRE) indicator to measure resource efficiency and circularity using the market value of resources as opposed to traditional approaches. This highlighted the range of available circularity metrics from being focused on product-level circularity informing about products being 'bad' or 'good' in terms of resource efficiency to being focused on value-based assessment of resource efficiency and CE related performance of supply chain actors.

\subsubsection{Industry applications and performance}

The implementation of CSCM at a micro level has increased in various industries (Nasir et al., 2017; Batista et al., 2018b; Hahladakis and Iacovidou, 2018; Jain et al., 2018; Laso et al., 2018; Leising et al., 2018; Stewart and Niero, 2018; Vlajic et al., 2018). For example, O'Connor et al. (2016) presented strategies for "Material Supply Chain Sustainability" using principles of Green Engineering and the vision of CE focused upon the electronics sector. Franco (2017) identified the challenges faced by incumbent firms in the textile industry along their value chains (from product design to take-back and reprocessing) in developing circular products. Mohamed Abdul Ghani et al. (2017) stressed on the need for systematic understanding and implementation of $\mathrm{CE}$ principles for $\mathrm{GHG}$ reduction across the construction supply chain industries in the US. Golev and Corder (2017) performed a detailed analysis of metal flows 
and values associated with e-waste in the Australian metal value chain. With an estimated metal recovery value from e-waste of about US\$ 370 million in 2014, the metal losses associated with e-waste are worth US\$ $60-70$ million a year, mainly due to $25 \%$ of e-waste being landfilled. Winans et al. (2017) focused on the application and assessment of CE in the industries representing critical research gaps (i.e., agricultural industries and chemical/biochemical industry products and value chains). The plastics and food supply chain wastes were concluded to provide interesting and viable organic "waste-to-resource" opportunities (Clark, 2017). Overall, the papers selected for the study revealed that integrating CE into SCM helped to improve environmental performance (Niero and Olsen, 2016; Genovese et al., 2017; Nasir et al., 2017) along with economic performance (Zhu et al., 2010, 2011).

\subsection{Integrating $C E$ into individual supply chain functions}

The transition towards CE requires considerable transformations in business models, supply chain configurations and practices related to product/service design, production, consumption, waste management, reuse, and recycling (Hobson, 2016; Mendoza et al., 2017). There were implications for logistics flows at all supply chain stages (Bicket et al., 2014). Consequently, some firms have adopted various micro-level CE practices (of organizations' operations and supply chains) (Ghisellini et al., 2016). These included eco-design or green design (Winkler, 2011), green procurement (Zhu et al., 2010), cleaner production and EoL management based on Reduction, Reuse and Recycle (3R principles) (Geng et al., 2012; Su et al., 2013; Lieder and Rashid, 2016).

Quite interestingly, Masi et al. (2017) discovered that since the emergence of CE in SCM, no new practices have been featured under the label of circular supply chain. Similarly, by 
analyzing the current CE implementation cases, Kalmykova et al. (2017) concluded that 'Recovery, Consumption and Use' parts of the value chain have received the most attention. Whereas, 'Manufacturing, Distribution and sales' are rarely involved in CE implementation.

\subsubsection{CE \& Product/Service Design}

Product/service design for CE has crucial roles in fostering materials and energy recirculation in CEs (Laurenti et al., 2015; Clark et al., 2016). Building upon CE and sustainability concepts, the product/service design functions need to be fundamentally changed as the product/service design greatly influences the whole product/service's value chain (De los Rios and Charnley, 2017; Jensen and Remmen, 2017). Sustainable packaging design and product labeling have also been regarded as important aspects of the circular design strategy (Bovea et al., 2018a; Bovea et al., 2018b; Steenis et al., 2018). Designers must respond to very different social, economic and environmental needs and must adopt holistic approaches to problem solving. They must change their design thinking and interpretation of associated practices that lead to the $\mathrm{CE}$ transition by creating products and services that match all inherent criteria of circular business model (Andrews, 2015; Sihvonen and Partanen, 2018). Moreover, the role of chemistry to provide the basis of innovative products (e.g., designed to be reused, recycled, or the feedstock renewed through natural processes) is crucial to creating a world without waste (Clark et al., 2016).

The current literature on design functions offers various design strategies and circular business models based on the notion of product life extension and closed loop systems (Bakker et al., 2014; Moreno et al., 2016; den Hollander et al., 2017; Sumter et al., 2018). Bocken et al. (2016) introduced the taxonomy of slowing, closing, and narrowing resource loops by building upon previous research. Moreno et al. (2016) developed a conceptual model and mapped the 
identified circular design strategies against circular business model archetypes. The den Hollander et al. (2017) team further extended Bocken's work by making a distinction between circular product design and eco-design. According to den Hollander et al. (2017), the waste hierarchy described in the European Waste Framework Directive (EC, 2009) is one of the guiding principles of eco-design, which details a priority order for managing waste, i.e. moving from prevention of waste, to reuse, recycling, recovery, and disposal. However, circular product design relates to Stahel (2010) work based on the Inertia Principle and to the concept of product integrity. Bovea and Pérez-Belis (2018) identified design guidelines required for a better circular product. Their study findings suggest that there is an urgent need to incorporate lifetime extension and product/component reuse guidelines in circular product design strategies.

Recently, the adoption of design for dismantling (DFD) has increased in many industrial sectors, partly motivated by recent technological advancements that offer cost savings besides extended product responsibility regulations. The DFD offers values to products not only at the EoL stage but also during the usage, life-time and maintenance stages (Sabaghi et al., 2016). Tian and Chen (2014) illustrated the use of the DFD method by reducing the number of incompatible polymers in vehicle dashboards. The DFD resulted in easy separation and recycling of polymers with mechanical methods, eliminated chemical separation methods. Vanegas et al. (2018) proposed a robust method, titled the 'ease of Disassembly Metric' (eDiM) to calculate the disassembly time modelled using the Maynard operation sequence technique (MOST). Important design implications (e.g., design for disassembly) for better CE were also presented in the computer industry (Talens Peiró et al., 2017) and in the crucial area of managing the supply of critical materials (Peck et al., 2015). 


\subsubsection{CE \& Procurement}

Introducing $\mathrm{CE}$ into the procurement function will re-define price, quality, time and value for money principles in procurement (Meehan and Bryde, 2011). The CE requires raw materials to be technically restorative or biologically regenerative so that there are no negative impacts upon the environment (Genovese et al., 2017). Green procurement has been a very active research topic (Blome et al., 2014). However, probably due to the newness of the CE philosophy, we only found three studies that integrated CE in procurement management.

Based on the CE principles, Witjes and Lozano (2016) proposed a public procurement framework which included technical and non-technical product/service specifications. The framework provides guidelines for reducing raw material utilization and improving resource efficiency through recovery and lower waste generation. A similar CE oriented study by Popa and Popa (2016) addressed the issue of green industrial acquisitions and focused on improving resource efficiency. It considered not only the environmental advantages and disadvantages of diverse options for industrial product acquisitions but also possibilities for complete reuse of the materials of the used products.

Integrating CE principles in SCM has been viewed as potentially viable for managing supply disruptions of critical and strategic materials. Sprecher et al. (2017) introduced resilience metrics for quantifying the resilience of critical material supply chains to disruptions based on CE principles. On the other hand, Gaustad et al. (2018) indicated that many firms are not able to allocate the required time and resources to track these dynamic, complex issues. They suggested that circularity strategies such as recycling, lean principles, dematerialization and diversification have a significant potential for reducing the vulnerabilities in material supply. 


\subsubsection{CE \& Production}

Reduction of resource consumption in the production processes has become essential for manufacturing industries to maintain competitiveness and survive in today's sustainability era (Ridaura et al., 2018). As a result, manufacturing industries have started adopting sustainable manufacturing practices and $\mathrm{CE}$ in their supply chains to mitigate environmental risks (Moktadir et al., 2018). In this context, green manufacturing has been widely recognized as a strategic model for sustainable development. It incorporates principles such as environmental protection, resource and energy conservation, waste reduction along with the production economy (Zhou et al., 2012). Rehman et al. (2016) argued that adopting green production practices not only offer long-term cost savings but also improve brand image, regulatory compliance, and investors' interest (Dubey et al., 2015). Yet, there are some concerns over increased operating cost for firms implementing green manufacturing (Mao and Wang, 2018).

Increasing material efficiency in terms of reduced generation of industrial waste, extraction and consumption of resources, energy demands and carbon emissions, have led to the development of many strategies in the manufacturing industry (Shahbazi et al., 2016). In order to achieve improved material efficiency in a CE context, green manufacturing (Zhou et al., 2012; Dubey et al., 2015; Rehman et al., 2016) and cleaner production (Brown and Stone, 2007; Cui and Song, 2009) are two highly relevant terms that are often used interchangeably in the literature as ways to help to achieve the needed improvements. We consider cleaner production to encompass green manufacturing as it covers not only manufacturing but also service activities. Cleaner production is defined as a production method which is not only concerned with people's needs, but also with environmental protection, energy conservation, and waste and emission reduction (Cui and Song, 2009). Cleaner production also seeks to prevent the use of non-renewable and harmful inputs (Ghisellini et al., 2016). In more general 
terms, cleaner production aims to increase overall economic efficiency while simultaneously reducing damage and risks for humans and the environment (Brown and Stone, 2007). Apparently, cleaner production is essential for achieving the CE vision (Li et al., 2010). However, cleaner production practices are yet to be fully implemented in many industries. For example, Ghisellini et al. (2018) found a predominant role of legislative and economic barriers in Chinese construction industry inhibiting companies to implement cleaner production practices.

Cleaner production has been a hot topic in production research. In fact, the Journal of Cleaner Production is devoted to the research topic and has grown in reputation and in the number of articles published each year in this area. Surprisingly, very few studies have explicitly integrated CE's circularity philosophy into cleaner production. Among the few exceptions, Li and Ma (2015) reported that integrating CE into cleaner production achieved significant energy savings and emission-reductions in a papermaking industry park in China. Leslie et al. (2016) developed a new screening method to investigate toxic chemicals and persistent organic pollutants (POP) including brominated diphenyl ether flame retardants (POP-BDEs) in order to promote cleaner production and to reduce human and ecological exposure to toxic, bio-accumulative and persistent chemicals via plastics. Antoniou and Zabaniotou (2015) presented waste-to-resource treatment of EoL tyres (ELT) using pyrolysis (i.e., decomposition brought about by high temperatures) from a cleaner production and $\mathrm{CE}$ approach. The pyrolysis method turned ELT into high-value solid material having absorptive properties along with heat conversation in the process. 
Overall, cleaner production practices are considered as a key enabler of CE practices at a micro level with implications for other supply chain functions such as circular product design, consumption and EoL and waste management (Sousa-Zomer et al., 2018a).

\subsubsection{CE and Logistics}

Both consumers and governmental legislation have pushed organizations to redesign their logistics networks to become more environmentally friendly while remaining cost efficient (Frota Neto et al., 2008). 'Green logistics' is recognized as producing and distributing goods in a sustainable way, taking account of environmental and social factors. This includes measuring the environmental impacts of various distribution strategies, reducing energy requirements in logistics-related activities, reducing wastages, and treatment of residual wastages (Sbihi and Eglese, 2010). While the focus has been on traditional logistics which seeks to organize forward distribution, i.e., the transport, warehousing, and inventory management from suppliers to customers, However, reverse logistics is also known to play a key role towards sustainable development (Sun, 2017).

$\mathrm{CE}$ is expected to have many implications for logistics management. So far, the efforts to integrate CE into logistics have mostly been observed in reverse logistics. Dhakal et al. (2016) highlighted the significant roles of secondary markets in extracting the value from products and also help to promote the reuse of products in relation to reverse logistics, $\mathrm{CE}$ and sustainability. Esposito et al. (2018) developed a conceptual model of a closed loop recovery system by integrating national postal service networks into reverse logistics to help to optimize CE functions. Among the quantitative works related to reverse logistics, Dente and Tavasszy (2018) introduced logistics modeling to explore the possible impacts of circular and functional economy on freight transportation and its emissions. Sun (2017) developed a measurement 
model to calculate carbon emissions from reverse logistics and explored factors influencing reverse logistics carbon footprints. Bernon et al. (2018) made an attempt to embed CE values in consumer retail reverse logistics operations.

\subsubsection{CE \& Consumption}

The CE philosophy has stimulated a shift towards a more sustainable consumption model in which valuable resources are reused and less waste is created (EMF, 2013). Consumption in the CE context and circular solutions is becoming an area of increased scholarly attention with particular interests in exploring drivers, barriers, the nature, meaning, and dynamics of circular consumption (Camacho-Otero et al., 2018). It is gaining traction in the global mobile phone market as a solution to increasing resource use (Wieser and Tröger, 2016). Canning (2006) studied electronic waste collection schemes in mobile phone supply chains in the UK. He suggested that consumers must cooperate to return unwanted phones and be willing to accept refurbished ones for the collection schemes to be effective. van Weelden et al. (2016) examined the main factors that influence consumers to accept refurbished mobile phones in Germany. They found that refurbished products are often rejected by consumers due to their lack of awareness of what the term actually entails. Wieser and Tröger (2016) studied consumers' motivations regarding mobile phones consumption in Austria using dimensions such as the timing of replacement, repair, and reuse of mobile phones. They found consumers' perceptions of obsolescence as a central consideration of mobile phone replacement, repair, and reuse. The findings of these three studies agreed with each other: the transition toward CE requires changes in consumer behaviors and they may be achieved by an awareness campaign and sustainability education. The product design function must be changed, however, to make it more optimal. For example, a Dutch company has now designed and is producing a totally 
repairable mobile phone. That will change consumer's attitudes dramatically or at least it should or might.

Jurgilevich et al. (2016) applied the CE philosophy in the sustainable food system in Finland for a transition towards a circular food system. They discussed challenges and potential solutions for circular production and consumption. Wang and Hazen (2016) studied the automobile industry in China. They found that information on cost, quality, and green attributes of remanufactured products affects consumers' perception of risk and value, which consequently influences consumers' purchase intentions of remanufactured products. Castellani et al. (2015) presented a case study of a second-hand goods shop and quantified the environmental benefits of reusing goods in terms of avoided impacts using life cycle assessment. They found a potential for significant avoided impacts by adopting sustainable consumption approaches (e.g., reuse) in many sectors including apparel, furniture, etc.

Overall, there is greater need to design appropriate policy and firm-level measures to enhance the awareness about circular consumption, noting that cultural differences play a significant role in framing consumer attitude towards circularity and nature in general (Gaur et al., 2018; Lakatos et al., 2018).

\subsubsection{CE \& EoL and Waste Management}

EoL and waste management in CSCM is considered critically important for recovering the remaining value within a product to its maximum utility (Cong, Liang et al., 2017). Recirculation of used components and materials has significant economic and environmental performance implications (van Loon and Van Wassenhove, 2017). However, there is a lack of understanding of the true potentials of EoL management for CE in many business sectors 
(Parajuly and Wenzel, 2017). In the extant literature, various EoL resource recovery approaches are discussed. These include: repurposing/recontextualizing, refurbishing, remanufacturing and recycling.

Repurposing has been described as the identification of a new use for a product that can no longer be used in its original form (Long et al., 2016). den Hollander et al. (2017) introduced a new term recontextualizing (replacing repurposing) for the use of an obsolete product or its components without any remedial actions in a different context than its originally designed use. In a CE context, a recent feasibility study based on a sample of 246 notebook computers found that $9 \%$ of the EoL notebooks could be repurposed as thin computers without incurring any cost (Coughlan et al., 2018).

Refurbishing is a process to restore used products to a functional and satisfactory condition, without dismantling the products completely (Rathore et al., 2011). Refurbishing can be applied to regain value from used products and to reduce waste. An efficient refurbishing process enables easy maintenance, recovery, and modification of products after the EoL cycle (van Weelden et al., 2016). However, there is a need to develop refurbishing guidelines and standards because the lack of them has led to variations in production, quality issues, and poor recognition of products (Sharma et al., 2016).

Remanufacturing recovers the residual value of used products by bringing them to a newlike condition (Debo et al., 2005). Typically, remanufacturing is preferred to other EoL processes because the remanufactured product is more environmentally friendly, higher in quality, and has a longer extended life (King et al., 2006; Hartwell and Marco, 2016). However, ambiguity surrounding the true meaning of other related $\mathrm{CE}$ activities such as: repair, 
reconditioning, refurbishment and uncertainty in managing intellectual property (IP) issues in many industries inhibit organizations from adopting a remanufacturing strategy (Hartwell and Marco, 2016). On the other hand, lack of consumer acceptance of remanufactured products throughout the world prevents supply chains from unlocking the full potential of remanufacturing (Hazen et al., 2017; Wang and Kuah, 2018). The diversity of product types, design features, and material compositions also pose serious policy and practical challenges (Zhang et al., 2011; Cong, L. et al., 2017a).

Various authors have suggested different strategies and ways to handle and optimize remanufacturing operations in a CE context. For example, Krystofik et al. (2018) introduced a term adaptive remanufacturing to suggest the use of an EoL product core to create a similar but non-identical product thus, enabling more viable lifecycles when compared to traditional remanufacturing. Zhang and Chen (2015) emphasized the adoption of more energy efficient and cleaner remanufacturing strategies. Jiang et al. (2016) used mathematical models to select an optimal remanufacturing process planning solution for the new arrival of used parts by utilizing the knowledge generated from remanufacturing of existing parts. Others have developed simulations for predicting the performance of remanufacturing systems operating under uncertainties (Low and $\mathrm{Ng}, 2018$ ) and various production control policies (Gaspari et al., 2017).

Our literature search also identified several examples of CE inspired recycling practices in different industries. The steel industry is regarded as an integral part of the CE model. Given the recyclable nature of the material itself, steel scrap is an important resource for steelmaking which can be recovered from products (Wübbeke and Heroth, 2014; Broadbent, 2016; Diener and Tillman, 2016). Despite having huge potential for increased profits, the literature highlights 
several barriers ranging from economic, policy, information, and technology-related barriers in recycling value chains, which prevent firms recycling and reusing metals (Wübbeke and Heroth, 2014; Golev and Corder, 2016; Densley Tingley et al., 2017). On the other hand, better regulations and effective use of taxation, encouraging R\&D in metals, establishment of extended producer responsibilities systems (Mo et al., 2009; Gumley, 2014) and use of robust forecasting models (Gauffin et al., 2016) were discussed as the possible remedies to the lack of metal recycling. In the construction industry, Jiménez-Rivero and García-Navarro (2016); (2017) developed performance indicators and presented best practices for the management of EoL gypsum under the framework of the European collaborative project GtoG (Gypsum to Gypsum) (Marlet, 2014). Tires and agricultural plastic waste recycling are other examples where pyrolysis technique has been successfully applied (Antoniou and Zabaniotou, 2015; Rentizelas et al., 2018). Recycling systems for post-consumer plastic packaging have huge potential to positively contribute towards circularity (Brouwer et al., 2018; Hahladakis et al., 2018).

Moreover, understanding the links between economic activities and waste generation is critically important to help achieve CE goals (Salemdeeb et al., 2016). Integrating CE into EoL \& waste management faces some practical challenges. Prevalent EoL materials management is concerned with collecting waste for material recovery (Singh and Ordoñez, 2016). However, to support other EoL processes, for example, reuse, the collection systems need to be improved to prevent physical damages to the EoL products during the collection process. Cobo et al. (2018) describe such a system as a circular integrated waste management system (CIWMS) that enhances the circularity of resources by strengthening the link between waste treatment and resource recovery. This is especially important in the case of waste electric and electronic (WEEE) products because they are often vulnerable to damage and the recovery or reuse of 
critical metals as a secondary supply source offers both economic and environmental benefits (Parajuly and Wenzel, 2017; Iş1ldar et al., 2018). With regard to minimizing transport emissions, mobile collection methods are found to be the lowest impact and a low total cost solution when compared with stationary collection methods (Nowakowski and Mrówczyńska, 2018).

Appropriate treatment of EoL products (particularly WEEE) has been a popular item on regulators' agendas (Atalay and Ravi, 2012). Many countries have adopted product take-back schemes based on the concept of extended producer responsibility (EPR) where producers are physically or financially responsible for the collection of EoL electronics and their recovery so as to divert hazardous materials away from landfills (Manomaivibool and Hong, 2014; Botelho et al., 2016; Favot et al., 2016; Polzer et al., 2016; Gu et al., 2017). Optimizing EPR schemes help to promote collection and recycling of both hazardous and critical materials by closing material loops and also incentivize eco-design (Richter and Koppejan, 2016).

\subsection{CE \& Supporting business Models}

The inability of prevalent linear economic models to manage the current sustainability issues has led to the development of new business models based on CE philosophy (Gorissen et al., 2016; Goyal et al., 2018). Nußholz (2017) defined circular business model (CBM) as "how a company creates, captures, and delivers value with the value creation logic designed to improve resource efficiency through contributing to extending useful life of products and parts (e.g., through long-life design, repair and remanufacturing) and closing material loops" (p.12). Linder and Williander (2017) further described the conceptual logic of creation logic in $\mathrm{CBM}$ as "utilizing the economic value retained in products after use in the production of new offerings" (p. 2). 
Several researchers have contributed to the development of CBMs. Roos (2014) outlined the process of CBM development and proposed specific questions for creating an appropriate business model for a circular value chain. Lüdeke-Freund et al. (2018) performed a morphological analysis of $26 \mathrm{CBMs}$ from literature to be able to identify a broad range of business model design options and proposed six major CBM patterns of closing resource loops. Bocken et al. (2017); Bocken et al. (2018) provide in-depth insights on how established businesses might pursue business model experimentation for sustainability and circularity goals.

Various business model frameworks have also been proposed in the extant literature. Lewandowski (2016) modified the traditional business model canvas and further included takeback systems and adoption factors to develop an extended framework for designing business models for CE. Mendoza et al. (2017) proposed a novel, 'backcasting and eco-design for the circular economy' (BECE) framework aimed at helping companies to develop sustainable business models that translate CE principles into industrial practices. The BECE framework has proven equally successfully in a product as well as service-oriented business applications (Heyes et al., 2018). Urbinati et al. (2017) proposed a taxonomy of CE business models to distinguish how some companies have implemented cost efficiency improvements in their adoption of CE. Their CE business model canvas framework introduced adoption of circularity along two dimensions: customer value proposition $\&$ interface (value proposition to customers) and value network (interaction with suppliers and restructuring internal activities). Recently, an environmental value propositions table (EVPT) and a step-by-step evaluation approach of CE business models were developed by Manninen et al. (2018). 
van Loon et al. (2017) provide an empirical evidence of the total cost of ownership for consumers and profitability for manufacturers in CBMs. Their study results provide interesting insights for firms wanting to make a transition from selling to leasing products in the presence of an effective second-hand market structure. However, it is important to note that moving from ownership to services (for example leasing) does not automatically contribute to environmental rents unless consumption patterns change accordingly (Junnila et al., 2018). For example, access-based services for cars are more successful when compared to smartphones where such models have largely failed (Hobson et al., 2018; Poppelaars et al., 2018). Lieder et al. (2018) present another example of customer preferences and acceptance of circular business model (pay per use washing machines) in Sweden.

In addition, many studies have identified and discussed the role of various drivers/enablers (Rizos et al., 2016; Mativenga et al., 2017; Veleva and Bodkin, 2017) as important factors for successful implementation of CBMs while others have identified barriers (Rizos et al., 2016; Linder and Williander, 2017; Spring and Araujo, 2017; Oghazi and Mostaghel, 2018; Singh and Giacosa, 2018; Sousa-Zomer et al., 2018b; Whalen et al., 2018) hindering the implementation of CBMs.

Product-Service Systems (PSS) represent a hybrid class of business model for CE (Vasantha et al., 2015). A PSS “consists of tangible products and intangible services designed and combined so that they are jointly capable of fulfilling specific needs of customers" (Tukker, 2015, p. 81). The PSSs exemplify a range of business models from being 'product orientated with a few extra services included' to more 'result-oriented' services with no predetermined product involved (Hobson, 2016; Yang et al., 2018). Pialot et al. (2017) further expanded the scope of PSS by proposing "Upgradable Product Service System (Up-PSS)". Up-PSS 
combines the upgradability concept with optimized maintenance, EoL management and the servitization of the offer. Product upgradability in a PSS context is further Khan et al. (2018) explained in the review paper. However, According to Kjaer et al. (2018) PSS does not automatically lead to achieving CE's vision of resource decoupling, i.e. decoupling economic growth from resource consumption. It only happens when there is a decrease in resource usage irrespective of the growth rate of the economic driver.

Overall, CBMs including PSSs promise significant cost savings and radical reductions in environmental impacts (Linder and Williander, 2017) in addition to improved entrepreneurial opportunities for services connected to products involving both forward and reverse supply chains (Spring and Araujo, 2017).

\subsection{CE \& Role of Technology/ Role of Technology in fostering CSCM}

A comprehensive understanding of how innovative and emerging technologies can support the transition towards CSCM is crucial. Yet, the research in this critical area is at infancy. Industry 4.0 term is used for the fourth industrial revolution that is enabled by smart technologies such as the Internet of Things (IoT), augmented reality, 3D printing (additive manufacturing), big data analytics, cloud computing, simulation, industrial automation and cybersecurity (Nascimento et al., 2018). Although, research concerning the integration of Industry 4.0 technologies into CSCM is in its early stages but there is already some clear evidence showing a promising future in line with achieving CE vision (Lopes de Sousa Jabbour et al., 2018).

In the last few years, WEEE has become a serious environmental issue given the rate of technological change and the throwaway culture in most consumer societies. Cong, L. et al. (2017b) claimed that most of the value recovery from EoL products (e.g., WEEE) is being 
carried out without rational planning, which results in a loss of recoverable value embedded in EoL materials and components. Esmaeilian et al. (2018) proposed an IoT enabled waste management (WEEE) framework for smart and zero waste sustainable cities while connecting waste management to the whole product life cycle. Their proposed framework is based on four interrelated strategies such as waste prevention, upstream waste separation, on-time waste collection, and proper value recovery of collected waste. In order to optimize the WEEE recycling process, Alvarez-de-los-Mozos and Renteria (2017) proposed the introduction of collaborative robots into the recycling lines to work in collaboration with humans in enhancing the recovery of valuable components and materials.

Giurco et al. (2014) discussed future trends in 3D printing and its possible application in CE. However, the entire discussion relied on conceptual scenarios given the lack of supporting business cases. While 3D printing offers substantial promise for CE but there are significant barriers in its way (Garmulewicz et al., 2018). Limited knowledge on the extent to which 3D printing affects the sustainability and circularity premises leaves more questions than answers (Despeisse et al., 2017). Zhong and Pearce (2018) present an interesting case of 3D printing application in a $\mathrm{CE}$ context. They upscaled the plastic waste from computer waste into 3D printing filament and produced valuable consumer products such as camera tripod, SD card holder and camera hood. The study results show significant economic and environmental benefits by tightening the CE loop.

Another stream of research relates to the roles of big data in CSCM. A recent paper documented a significant impact of big data and predictive analytics on the supply chain sustainability performance (Dubey et al., 2017b). However, our review identified only one study related to the application of big data in CE. Jabbour et al. (2017) in their research 
proposed a framework of CE and large-scale data (big data) in CE. They presented a relational matrix illustrating the complexities of $\mathrm{CE}$, big data and stakeholder management in $\mathrm{CE}$. They developed several propositions to advance the literature in this emerging field.

\section{Future Research Directions}

The review presented above showed that $\mathrm{CSCM}$ is still an emerging research field. Most relevant publications are conceptual works and case studies, which is typical for a research field that is still at its infancy. A few specific research topics in CSCM, including supply chain performance and EoL product management, have received relatively more attention. Nevertheless, much more research work must be done on all supply chain functions in order to reap the full potential of CSCM. There are many technical, process, and incentive issues to overcome for making $\mathrm{CE}$ a reality. We, therefore, call for research in the following directions that are important to CSCM but have received very little or no attention. Based on the review results, Table 5 outlines the importance of each research direction, the extent of relevant knowledge gap, potential impact of conducting research in the research direction, and the urgency for further research. Given that CE is a promising new frontier in sustainable thinking, we believe that advancing CSCM in the following areas will substantially enhance SSCM and GSCM to aid organizations to achieve a higher level of sustainability performance. 
Table 5: Summary of future research directions in CSCM

\begin{tabular}{|l|c|c|c|c|}
\hline \multicolumn{1}{|c|}{$\begin{array}{c}\text { Future research } \\
\text { directions }\end{array}$} & Importance & $\begin{array}{c}\text { Knowledge } \\
\text { gap }\end{array}$ & $\begin{array}{c}\text { Potential } \\
\text { impact }\end{array}$ & Urgency \\
\hline Design for circularity & Very high & Very large & Critical & Very urgent \\
\hline Procurement and CSCM & High & Very large & Moderate & Urgent \\
\hline $\begin{array}{l}\text { Biodegradable packaging } \\
\text { for CSCM }\end{array}$ & Very high & Large & Critical & Very urgent \\
\hline $\begin{array}{l}\text { Circular supply chain } \\
\text { collaboration and } \\
\text { coordination }\end{array}$ & Very high & Large & Critical & Very urgent \\
\hline $\begin{array}{l}\text { Identifying drivers and } \\
\text { barriers of CSCM }\end{array}$ & Very High & Large & Critical & Very urgent \\
\hline Circular consumption & High & Large & Moderate & Urgent \\
\hline $\begin{array}{l}\text { Product liabilities and } \\
\text { producer's responsibility }\end{array}$ & Very high & Very large & Critical & Very urgent \\
\hline Technologies and CSCM & High & Very Large & Critical & Urgent \\
\hline
\end{tabular}

Design for circularity: It is clear that $\mathrm{CSCM}$ requires a complete rethinking of the way products, processes, and supply chains are designed (Bakker et al., 2014; Aminoff and Kettunen, 2016; Flink, 2017). Design for circularity is a cornerstone of CSCM. Ample research opportunities exist in $\mathrm{CE}$ driven processes innovations, supply chain design for EoL management, and new product design methods/techniques including DFD (Tian and Chen, 2014), design for remanufacturing (Ijomah et al., 2007), and design for recycling (Gaustad et al., 2010).

Procurement and CSCM: Procurement is a strategic function of many organizations, playing a vital role in a firm's sustainability performance. Surprisingly, much less research has been conducted on integrating circular thinking in procurement than in most other supply chain functions. The CSCM requires product with new or stronger features such as durability, reliability, and reusability to support life cycle extension, easy recovery of resources, and 
minimal wastages. More research is needed to integrate CE oriented performance indicators into procurement and supplier management (Nissinen et al., 2009) to reduce the environmental impacts of products/services throughout their life cycle (Tarantini et al., 2011).

Biodegradable packaging for CSCM: Every year, the world produces millions of tons of non-biodegradable plastics for packaging which creates severe environmental problems (Mohanty et al., 2000). For example, in China, packaging waste is the 4th largest source of pollution (Zhang and Zhao, 2012). The new, CSCM requires packaging materials to have characteristics such as availability from renewable sources, recyclability, and composability. They should also be of low cost and should possess physical and chemical properties for easy customization for diverse uses. Recently, significant progress has been made in obtaining biodegradable packaging materials such as polylactide (PLA), an aliphatic polyester (Ahmed and Varshney, 2011), and polysaccharide (SSPS) based on soluble soybean products (Tajik et al., 2013). Packaging solutions based on biodegradable materials deserve much future research and investments for enhancing the rate of transition to CEs.

Circular supply chain collaboration and coordination: In a CE, waste residuals from a process/supply chain become resources for another process/supply chain. This requires longterm collaboration not only among supply chain partners (Flink, 2017) but also among different supply chains. Many research opportunities lie in the areas of incentives and strategic value alignment (Genovese et al., 2017), collaboration and coordination mechanisms including contracts, supply chain integration, and knowledge management with suppliers, customers, and other stakeholders to keep used products/components/materials in circulation (Aminoff and Kettunen, 2016; Grimm et al., 2016; Stewart and Niero, 2018). 
Drivers and barriers of CSCM: Drivers and barriers of CSCM are likely to vary in different contexts. So far, only a few studies have investigated challenges in the information technologies (IT) and electronics industries in China (Park et al., 2010), and textile (Flink, 2017) and retail industries in Finland (Aminoff and Kettunen, 2016). Investigations are urgently needed on how cultural and industrial sector-specifics contexts affect the drivers and barriers of CSCM. Furthermore, research is necessary to prioritize the drivers and barriers in a specific context in order to devise the most effective intervention policies to prevent and/or to overcome them.

Circular consumption: Despite a few early studies (Canning, 2006; Xue and Yang, 2010; Jurgilevich et al., 2016; van Weelden et al., 2016; Wang and Hazen, 2016), the consumer perspective on circular products has been largely unexplored. More research is required to explore how circular products can be made more appealing to customers. For example, marketing strategies based on demonstrating product reliability, innovative offerings, warranty, and assurance of quality control mechanisms may be developed to shape positive consumer attitudes towards circular products (Hazen et al., 2017). Given that many consumers are unwilling to return used products (van Weelden et al., 2016), it is important to study strategies and incentives for changing consumer behaviors to support the cause of circularity.

Product liabilities and producer's responsibility: The expansion of CEs will require systematic product take-back by producers to recover resources through EoL management. Therefore, EoL and waste management scenarios must address:

- Liability due to toxic substances used in production or usage of the products causing a new set of human health and environmental health consequences.

- Liability due to malfunctioning of products. 
- Liability due to mismanagement of materials during the life cycle or lives cycles of substances used in the synthesis and production of products as well as in the operation of products and in the management of materials at the EOL/recycling phases.

Future research is needed to investigate the feasibility and effectiveness of an extended producer responsibility legislation (King et al., 2006; Zhu et al., 2010) to hold producers accountable for their products, even long after a sale to end customers. An alternative approach is PSS, a 'functional service' model in which the producers retain the ownership of physical products and act as service providers focusing on the service end user wants (Nasir et al., 2017). The PSS systems can be designed to help to facilitate EoL management by manufacturers. It can substantially reduce the need of production activities in a shared economy, resulting in lower environmental impacts (Tukker, 2015).

Technologies and CSCM: Technologies can be an enabler of sustainable development, but their role in CSCM has not been well researched. Recently, the Journal of Cleaner Production published a special issue titled "Improving natural resource management and human health to ensure sustainable societal development based upon insights gained from working within 'Big Data Environments" A review of waste prevention through 3R under the concept of circular economy in China. However, none of the included papers integrated circular thinking! Ample room is left for exploring big data analytics for CSCM. Also, 3D printing, another promising technology, has become an important driving force for realizing high-efficiency and low-cost customized production. Researchers need to investigate the CE issues arising from the proliferation of product varieties and the consequent short lifecycle of customized products (Helen et al., 2016; Despeisse et al., 2017). 
In addition, the internet of things (IoT) and Radio Frequency Identification (RFID) technologies can be used in CSCM to improve traceability and to enhance lifecycle information management (Zhang et al., 2010). Moreover, there is an urgent need to integrate the CE principles into an enterprises' information systems (EIS) (Jensen and Remmen, 2017).

\section{Conclusions}

The evolving visions and actions in planning and implementing CEs have been increasingly recognized as better alternatives than the prevalent linear (take, make, dispose) economic model. It offers much potential to help organizations achieve breakthroughs in sustainability performance. Consequently, integrating $\mathrm{CE}$ into SCM has received growing research interest. However, many confusions on the terms related to supply chain sustainability remain. It was argued in this study that the advancement of the field is hindered by the lack of understanding of what CSCM actually entails and which research directions are of strategic importance. In response, we provided a definition of CSCM out of the broader literature. Using this definition as a base we then conducted a structured review of the literature to gain an in-depth understanding of the current status of CSCM research. The field is promising and warrants many further studies using the CSCM conceptualization presented in this paper which covers restorative and regenerative processes, appropriate business models (closed and open loop) and supply chain functions (reorientation) to achieve a zero-waste vision. Finally, the authors suggested future research directions (summarized in Table 5) based on the importance of the research direction, current knowledge gap in the extant literature, potential impact of future research on the research direction and the level of urgency required for action and implementation. Overall, the research provided timely guidance to help researchers, practitioners, and policy-makers to understand how to operationalize CEs from a supply chain perspective to substantially enhance SSCM and GSCM. 
This literature review has some limitations. We have only reviewed publications in English. There might be an important loss of knowledge for not including publications in other languages. Some relevant publications in the forms of conference papers, industry reports, books, and book chapters were cited in this research paper. However, they were not included in the structured literature review as the review methodology deliberately focused on academic journal articles to ensure the quality of the publications reviewed. The field of CSCM is developing rapidly. Therefore, it is necessary to update the literature review in a few years' time to keep up with the progress of the research field. We hope that this literature review will help to accelerate the transition to equitable, sustainable, livable, post-fossil carbon societies. We invite readers to provide feedback for further advancing this promising research field.

\section{Acknowledgements}

This work was supported by National Natural Science Foundation of China (51875251, 71872072), Natural Science Foundation of Guangdong (China) (2016A030311041), Blue Fire Project (Huizhou) Industry-University-Research Joint Innovation Fund of Ministry of Education (China) (CXZJHZ201722), the Fundamental Research Funds for the Central Universities (China) (11618401).

\section{References}

Ahi, P., Searcy, C., 2013. A comparative literature analysis of definitions for green and sustainable supply chain management. Journal of Cleaner Production 52, 329-341.

Ahi, P., Searcy, C., 2015. An analysis of metrics used to measure performance in green and sustainable supply chains. Journal of Cleaner Production 86(Supplement C), 360-377.

Ahmed, J., Varshney, S.K., 2011. Polylactides-Chemistry, Properties and Green Packaging Technology: A Review. International Journal of Food Properties 14(1), 37-58.

Alvarez-de-los-Mozos, E., Renteria, A., 2017. Collaborative Robots in e-waste Management. Procedia Manuf. 11, 55-62. 
Aminoff, A., Kettunen, O., 2016. Sustainable Supply Chain Management in a Circular EconomyTowards Supply Circles, in: Setchi, R., Howlett, R.J., Liu, Y., Theobald, P. (Eds.), Sustainable Design and Manufacturing 2016. Springer International Publishing, Cham, pp. 61-72.

Andersen, M.S., 2007. An introductory note on the environmental economics of the circular economy. Sustainability Sci. 2(1), 133-140.

Andrews, D., 2015. The circular economy, design thinking and education for sustainability. Local Econ. 30(3), 305-315.

Anne, T., Helen, W., 2015. Theories in sustainable supply chain management: a structured literature review. International Journal of Physical Distribution \& Logistics Management 45(1/2), 16-42.

Ansari, Z.N., Kant, R., 2017. A state-of-art literature review reflecting 15 years of focus on sustainable supply chain management. Journal of Cleaner Production 142(Part 4), 2524-2543.

Antoniou, N., Zabaniotou, A., 2015. Experimental proof of concept for a sustainable End of Life Tyres pyrolysis with energy and porous materials production. Journal of Cleaner Production 101, 1-14.

Atalay, A., Ravi, S., 2012. Extended Producer Responsibility for E-Waste: Individual or Collective Producer Responsibility? Production and Operations Management 21(6), 1042-1059.

Bakker, C., Wang, F., Huisman, J., Den Hollander, M., 2014. Products that go round: Exploring product life extension through design. Journal of Cleaner Production 69, 10-16.

Batista, L., Bourlakis, M., Smart, P., Maull, R., 2018a. In search of a circular supply chain archetype-a content-analysis-based literature review. Prod Plann Control 29(6), 438-451.

Batista, L., Gong, Y., Pereira, S., Jia, F., Bittar, A., 2018b. Circular supply chains in emerging economiesa comparative study of packaging recovery ecosystems in China and Brazil. Int J Prod Res.

Bernon, M., Tjahjono, B., Ripanti, E.F., 2018. Aligning retail reverse logistics practice with circular economy values: an exploratory framework. Prod Plann Control 29(6), 483-497.

Bicket, M., Guilcher, S., Hestin, M., Hudson, C., Razzini, P., Tan, A., ten Brink, P., van Dijl, E., Vanner, R., Watkins, E., 2014. Scoping study to identify potential circular economy actions, priority sectors, material flows and value chains. http://bookshop.europa.eu/en/scoping-study-to-identify-potentialcircular-economy-actions-priority-sectors-material-flows-and-value-chains-pbKH0114775/. (Accessed 25/02/2018).

Blome, C., Hollos, D., Paulraj, A., 2014. Green procurement and green supplier development: antecedents and effects on supplier performance. Int J Prod Res 52(1), 32-49.

Bocken, N.M.P., de Pauw, I., Bakker, C., van der Grinten, B., 2016. Product design and business model strategies for a circular economy. J. Ind. Prod. Eng. 33(5), 308-320.

Bocken, N.M.P., Miller, K., Weissbrod, I., Holgado, M., Evans, S., 2017. Business model experimentation for circularity: Driving sustainability in a large international clothing retailer. Econo. 2017(1), 85-122.

Bocken, N.M.P., Schuit, C.S.C., Kraaijenhagen, C., 2018. Experimenting with a circular business model: Lessons from eight cases. Environmental Innovation and Societal Transitions 28, 79-95. 
Botelho, A., Ferreira Dias, M., Ferreira, C., Pinto, L.M.C., 2016. The market of electrical and electronic equipment waste in Portugal: Analysis of take-back consumers' decisions. Waste Manage. Res. 34(10), 1074-1080.

Bovea, M.D., Ibáñez-Forés, V., Pérez-Belis, V., Juan, P., Braulio-Gonzalo, M., Díaz-ávalos, C., 2018a. Incorporation of circular aspects into product design and labelling: Consumer preferences. Sustainability 10(7).

Bovea, M.D., Pérez-Belis, V., 2018. Identifying design guidelines to meet the circular economy principles: A case study on electric and electronic equipment. Journal of Environmental Management 228, 483-494.

Bovea, M.D., Quemades-Beltrán, P., Pérez-Belis, V., Juan, P., Braulio-Gonzalo, M., Ibáñez-Forés, V., 2018b. Options for labelling circular products: Icon design and consumer preferences. Journal of Cleaner Production 202, 1253-1263.

Bressanelli, G., Adrodegari, F., Perona, M., Saccani, N., 2018a. Exploring how usage-focused business models enable circular economy through digital technologies. Sustainability 10(3).

Bressanelli, G., Perona, M., Saccani, N., 2018b. Challenges in supply chain redesign for the Circular Economy: a literature review and a multiple case study. Int J Prod Res.

Broadbent, C., 2016. Steel's recyclability: demonstrating the benefits of recycling steel to achieve a circular economy. Int. J. Life Cycle Assess. 21(11), 1658-1665.

Brouwer, M.T., Thoden van Velzen, E.U., Augustinus, A., Soethoudt, H., De Meester, S., Ragaert, K., 2018. Predictive model for the Dutch post-consumer plastic packaging recycling system and implications for the circular economy. Waste Management 71, 62-85.

Brown, G., Stone, L., 2007. Cleaner production in New Zealand: taking stock. Journal of Cleaner Production 15(8), 716-728.

Camacho-Otero, J., Boks, C., Pettersen, I.N., 2018. Consumption in the circular economy: A literature review. Sustainability 10(8).

Canning, L., 2006. Rethinking market connections: mobile phone recovery, reuse and recycling in the UK. Journal of Business \& Industrial Marketing 21(5), 320-329.

Carter, R.C., Dale, S.R., 2008. A framework of sustainable supply chain management: moving toward new theory. International Journal of Physical Distribution \& Logistics Management 38(5), 360-387.

Castellani, V., Sala, S., Mirabella, N., 2015. Beyond the throwaway society: A life cycle-based assessment of the environmental benefit of reuse. Integr. Environ. assess. manage. 11(3), 373-382.

Chakraborty, S., 2010. Concise chronological road map of evolving green supply chain management concepts: a review. IUP Journal of Supply Chain Management 7(4), 7-25.

Clark, J.H., 2017. From waste to wealth using green chemistry: The way to long term stability. Curr. Opin. Green Sustain. Chem. 8, 10-13.

Clark, J.H., Farmer, T.J., Herrero-Davila, L., Sherwood, J., 2016. Circular economy design considerations for research and process development in the chemical sciences. Green Chem. 18(14), 3914-3934. 
Cobo, S., Dominguez-Ramos, A., Irabien, A., 2018. From linear to circular integrated waste management systems: a review of methodological approaches. Resour. Conserv. Recycl. 135, 279-295. Cong, L., Zhao, F., Sutherland, J.W., 2017a. Integration of dismantling operations into a value recovery plan for circular economy. Journal of Cleaner Production 149, 378-386.

Cong, L., Zhao, F., Sutherland, J.W., 2017. Product Redesign for Improved Value Recovery via Disassembly Bottleneck Identification and Removal. Procedia CIRP 61(Supplement C), 81-86.

Cong, L., Zhao, F., Sutherland, J.W., 2017b. Value recovery from end-of-use products facilitated by automated dismantling planning. Clean Technol. Environ. Policy 19(7), 1867-1882.

Coughlan, D., Fitzpatrick, C., McMahon, M., 2018. Repurposing end of life notebook computers from consumer WEEE as thin client computers - A hybrid end of life strategy for the Circular Economy in electronics. Journal of Cleaner Production 192, 809-820.

Craig, R.C., Easton, P.L., 2011. Sustainable supply chain management: evolution and future directions. International Journal of Physical Distribution \& Logistics Management 41(1), 46-62.

Cui, H., Song, X., 2009. The Study on Countermeasures of Promoting Energy-Saving and EmissionsReducing Based on Circular Economy Theory, 2009 IITA International Conference on Services Science, Management and Engineering. pp. 333-335.

Darom, N.A.M., Hishamuddin, H., 2016. Integration of economic and environmental aspects in sustainable supply chain management: A review, Proceedings of the 6th International Conference on Industrial Engineering and Operations Management, Kuala Lumpur, Malaysia. pp. 8-10.

De Angelis, R., Howard, M., Miemczyk, J., 2018. Supply chain management and the circular economy: towards the circular supply chain. Prod Plann Control 29(6), 425-437.

De los Rios, I.C., Charnley, F.J.S., 2017. Skills and capabilities for a sustainable and circular economy: The changing role of design. Journal of Cleaner Production 160(Supplement C), 109-122.

Debo, L.G., Toktay, L.B., Wassenhove, L.N.V., 2005. Market Segmentation and Product Technology Selection for Remanufacturable Products. Management Science 51(8), 1193-1205.

den Hollander, M.C., Bakker, C.A., Hultink, E.J., 2017. Product Design in a Circular Economy: Development of a Typology of Key Concepts and Terms. J. Ind. Ecol. 21(3), 517-525.

Densley Tingley, D., Cooper, S., Cullen, J., 2017. Understanding and overcoming the barriers to structural steel reuse, a UK perspective. Journal of Cleaner Production 148, 642-652.

Dente, S.M.R., Tavasszy, L.A., 2018. Impacts of trade related sustainability strategies on freight transportation: Modelling framework and application for France. Transp. Res. Part D Transp. Environ. 58, 308-319.

Despeisse, M., Baumers, M., Brown, P., Charnley, F., Ford, S.J., Garmulewicz, A., Knowles, S., Minshall, T.H.W., Mortara, L., Reed-Tsochas, F.P., Rowley, J., 2017. Unlocking value for a circular economy through 3D printing: A research agenda. Technol. Forecast. Soc. Change 115, 75-84.

Dhakal, M., Smith, M.H., Newbery, R., 2016. Secondary market: A significant aspect in reverse logistics and sustainability. Int. J. Sustainability Econ. Soc. Cult. Context 12(1), 24-35. 
Di Maio, F., Rem, P.C., Baldé, K., Polder, M., 2017. Measuring resource efficiency and circular economy: A market value approach. Resour. Conserv. Recycl. 122, 163-171.

Diener, D.L., Tillman, A.M., 2016. Scrapping steel components for recycling - Isn't that good enough? Seeking improvements in automotive component end-of-life. Resour. Conserv. Recycl. 110, 48-60.

Du, L., Lianqing, Y., Rao, C., 2010. The construction research on Rapid-Response Eco-Supply Chain of the textile industry based on the circular economy, International Conference on E-Health Networking Digital Ecosystems and Technologies (EDT). pp. 248-251.

Dubey, R., Gunasekaran, A., Childe, S.J., Papadopoulos, T., Fosso Wamba, S., 2017a. World class sustainable supply chain management: critical review and further research directions. The International Journal of Logistics Management 28(2), 332-362.

Dubey, R., Gunasekaran, A., Childe, S.J., Papadopoulos, T., Luo, Z., Wamba, S.F., Roubaud, D., 2017b. Can big data and predictive analytics improve social and environmental sustainability? Technol. Forecast. Soc. Change.

Dubey, R., Gunasekaran, A., Samar Ali, S., 2015. Exploring the relationship between leadership, operational practices, institutional pressures and environmental performance: A framework for green supply chain. Int J Prod Econ 160(Supplement C), 120-132.

EC (European Commission), 2009. Directive 2008/98/EC of the European Parliament and of the Council of 19 November 2008 on waste and repealing certain Directives. http://eurlex.europa.eu/eli/dir/2008/98/oj. (Accessed 15/03/2018).

Elkington's, J., 2004. Enter the triple bottom line. The triple bottom line: Does it all add up 11(12), 116.

EMF (Ellen MacArthur Foundation), 2012. Towards the circular economy. https://www.ellenmacarthurfoundation.org/publications/towards-the-circular-economy-vol-1-aneconomic-and-business-rationale-for-an-accelerated-transition. (Accessed 14/03/2018).

EMF (Ellen MacArthur Foundation), 2013. Towards the Circular Economy: Economic and Business Rationale for an Accelerated Transition.

EMF (Ellen MacArthur Foundation), 2014. Towards the circular economy: Accelerating the scale-up across global supply chains.

EMF (Ellen MacArthur Foundation), 2017. What is a circular economy? https://www.ellenmacarthurfoundation.org/circular-economy. (Accessed 14/03/2018).

Esmaeilian, B., Wang, B., Lewis, K., Duarte, F., Ratti, C., Behdad, S., 2018. The future of waste management in smart and sustainable cities: A review and concept paper. Waste Management 81, 177-195.

Esposito, M., Tse, T., Soufani, K., 2018. Reverse logistics for postal services within a circular economy. Thunderbird Int. Bus. Rev. 60(5), 741-745.

Fahimnia, B., Sarkis, J., Davarzani, H., 2015. Green supply chain management: A review and bibliometric analysis. Int J Prod Econ 162, 101-114. 
Favot, M., Veit, R., Massarutto, A., 2016. The evolution of the Italian EPR system for the management of household Waste Electrical and Electronic Equipment (WEEE). Technical and economic performance in the spotlight. Waste Management 56, 431-437.

Flink, A., 2017. Ecological supply chain in circular economy: Adopting circular economy principles in cotton textile supply chain Case: Finlayson Ltd.

Franco, M.A., 2017. Circular economy at the micro level: A dynamic view of incumbents' struggles and challenges in the textile industry. Journal of Cleaner Production 168, 833-845.

Frota Neto, J.Q., Bloemhof-Ruwaard, J.M., van Nunen, J.A.E.E., van Heck, E., 2008. Designing and evaluating sustainable logistics networks. Int J Prod Econ 111(2), 195-208.

Gao, D., Xu, Z., Ruan, Y.Z., Lu, H., 2017. From a systematic literature review to integrated definition for sustainable supply chain innovation (SSCI). Journal of Cleaner Production 142(Part 4), 1518-1538.

Garmulewicz, A., Holweg, M., Veldhuis, H., Yang, A., 2018. Disruptive Technology as an Enabler of the Circular Economy: What Potential Does 3D Printing Hold? Calif. Manage. Rev. 60(3), 112-132.

Gaspari, L., Colucci, L., Butzer, S., Colledani, M., Steinhilper, R., 2017. Modularization in material flow simulation for managing production releases in remanufacturing. J. Remanuf. 7(2-3), 139-157.

Gauffin, A., Andersson, N.Å.I., Storm, P., Tilliander, A., Jönsson, P.G., 2016. The global societal steel scrap reserves and amounts of losses. Resources 5(3).

Gaur, J., Mani, V., Banerjee, P., Amini, M., Gupta, R., 2018. Towards building circular economy: A crosscultural study of consumers' purchase intentions for reconstructed products. Manage. Decis.

Gaustad, G., Krystofik, M., Bustamante, M., Badami, K., 2018. Circular economy strategies for mitigating critical material supply issues. Resour. Conserv. Recycl. 135, 24-33.

Gaustad, G., Olivetti, E., Kirchain, R., 2010. Design for Recycling. J. Ind. Ecol. 14(2), 286-308.

Geng, Y., Fu, J., Sarkis, J., Xue, B., 2012. Towards a national circular economy indicator system in China: an evaluation and critical analysis. Journal of Cleaner Production 23(1), 216-224.

Genovese, A., Acquaye, A.A., Figueroa, A., Koh, S.C.L., 2017. Sustainable supply chain management and the transition towards a circular economy: Evidence and some applications. Omega 66, 344-357. Ghisellini, P., Cialani, C., Ulgiati, S., 2016. A review on circular economy: The expected transition to a balanced interplay of environmental and economic systems. Journal of Cleaner Production 114, 11 32.

Ghisellini, P., Ji, X., Liu, G., Ulgiati, S., 2018. Evaluating the transition towards cleaner production in the construction and demolition sector of China: A review. Journal of Cleaner Production 195, 418-434.

Giurco, D., Littleboy, A., Boyle, T., Fyfe, J., White, S., 2014. Circular economy: Questions for responsible minerals, additive manufacturing and recycling of metals. Resources 3(2), 432-453.

Golev, A., Corder, G.D., 2016. Typology of options for metal recycling: Australia's perspective. Resources 5(1).

Golev, A., Corder, G.D., 2017. Quantifying metal values in e-waste in Australia: The value chain perspective. Minerals Eng 107, 81-87. 
Gorissen, L., Vrancken, K., Manshoven, S., 2016. Transition thinking and business model innovationtowards a transformative business model and new role for the reuse centers of Limburg, Belgium. Sustainability 8(2).

Govindan, K., Hasanagic, M., 2018. A systematic review on drivers, barriers, and practices towards circular economy: a supply chain perspective. Int J Prod Res, 1-34.

Govindan, K., Soleimani, H., 2017. A review of reverse logistics and closed-loop supply chains: a Journal of Cleaner Production focus. Journal of Cleaner Production 142(Part 1), 371-384.

Govindan, K., Soleimani, H., Kannan, D., 2015. Reverse logistics and closed-loop supply chain: A comprehensive review to explore the future. European Journal of Operational Research 240(3), 603626.

Goyal, S., Esposito, M., Kapoor, A., 2018. Circular economy business models in developing economies: Lessons from India on reduce, recycle, and reuse paradigms. Thunderbird Int. Bus. Rev. 60(5), 729740.

Grimm, J.H., Hofstetter, J.S., Sarkis, J., 2016. Exploring sub-suppliers' compliance with corporate sustainability standards. Journal of Cleaner Production 112, Part 3, 1971-1984.

Gu, Y., Wu, Y., Xu, M., Wang, H., Zuo, T., 2017. To realize better extended producer responsibility: Redesign of WEEE fund mode in China. Journal of Cleaner Production 164, 347-356.

Guide, V.D.R., Van Wassenhove, L.N., 2006. Closed-Loop Supply Chains: An Introduction to the Feature Issue (Part 1). Production and Operations Management 15(3), 345-350.

Gumley, W., 2014. An analysis of regulatory strategies for recycling and re-use of metals in Australia. Resources 3(2), 395-415.

Gurtu, A., Searcy, C., Jaber, M., 2015. An analysis of keywords used in the literature on green supply chain management. Manage. Res. Rev. 38(2), 166-194.

Hahladakis, J.N., lacovidou, E., 2018. Closing the loop on plastic packaging materials: What is quality and how does it affect their circularity? Sci. Total Environ. 630, 1394-1400.

Hahladakis, J.N., Purnell, P., lacovidou, E., Velis, C.A., Atseyinku, M., 2018. Post-consumer plastic packaging waste in England: Assessing the yield of multiple collection-recycling schemes. Waste Management 75, 149-159.

Harland, C.M., Lamming, R.C., Walker, H., Phillips, W.E., Caldwell, N.D., Johnsen, T.E., Knight, L.A., Zheng, J., 2006. Supply management: is it a discipline? International Journal of Operations \& Production Management 26(7), 730-753.

Hartwell, I., Marco, J., 2016. Management of intellectual property uncertainty in a remanufacturing strategy for automotive energy storage systems. J. Remanuf. 6(1).

Hazen, B.T., Mollenkopf, D.A., Wang, Y., 2017. Remanufacturing for the Circular Economy: An Examination of Consumer Switching Behavior. Business Strategy and the Environment 26(4), 451-464. Helen, R., Norbert, B., Kulwant, S.P., 2016. 3D printing services: classification, supply chain implications and research agenda. International Journal of Physical Distribution \& Logistics Management 46(10), 886-907. 
Heyes, G., Sharmina, M., Mendoza, J.M.F., Gallego-Schmid, A., Azapagic, A., 2018. Developing and implementing circular economy business models in service-oriented technology companies. Journal of Cleaner Production 177, 621-632.

Hobson, K., 2016. Closing the loop or squaring the circle? Locating generative spaces for the circular economy. Progress in Human Geography 40(1), 88-104.

Hobson, K., Lynch, N., Lilley, D., Smalley, G., 2018. Systems of practice and the Circular Economy: Transforming mobile phone product service systems. Environmental Innovation and Societal Transitions 26, 147-157.

Howard, M., Hopkinson, P., Miemczyk, J., 2018. The regenerative supply chain: a framework for developing circular economy indicators. Int J Prod Res.

Huybrechts, D., Derden, A., Van den Abeele, L., Vander Aa, S., Smets, T., 2018. Best available techniques and the value chain perspective. Journal of Cleaner Production 174, 847-856.

Ijomah, W.L., McMahon, C.A., Hammond, G.P., Newman, S.T., 2007. Development of robust designfor-remanufacturing guidelines to further the aims of sustainable development. Int J Prod Res 45(1819), 4513-4536.

Işıldar, A., Rene, E.R., van Hullebusch, E.D., Lens, P.N.L., 2018. Electronic waste as a secondary source of critical metals: Management and recovery technologies. Resour. Conserv. Recycl. 135, 296-312.

Jabbour, C.J.C., Jabbour, A.B.L.D.S., Sarkis, J., Filho, M.G., 2017. Unlocking the circular economy through new business models based on large-scale data: An integrative framework and research agenda. Technol. Forecast. Soc. Change.

Jain, S., Jain, N.K., Metri, B., 2018. Strategic framework towards measuring a circular supply chain management. Benchmarking 25(8), 3238-3252.

Jensen, J.P., Remmen, A., 2017. Enabling Circular Economy Through Product Stewardship. Procedia Manuf. 8, 377-384.

Jiang, Z., Jiang, Y., Wang, Y., Zhang, H., Cao, H., Tian, G., 2016. A hybrid approach of rough set and case-based reasoning to remanufacturing process planning. J Intell Manuf, 1-14.

Jiménez-Rivero, A., García-Navarro, J., 2016. Indicators to Measure the Management Performance of End-of-Life Gypsum: From Deconstruction to Production of Recycled Gypsum. Waste Biomass Valoris. 7(4), 913-927.

Jiménez-Rivero, A., García-Navarro, J., 2017. Best practices for the management of end-of-life gypsum in a circular economy. Journal of Cleaner Production 167, 1335-1344.

Junnila, S., Ottelin, J., Leinikka, L., 2018. Influence of reduced ownership on the environmental benefits of the circular economy. Sustainability 10(11).

Jurgilevich, A., Birge, T., Kentala-Lehtonen, J., Korhonen-Kurki, K., Pietikäinen, J., Saikku, L., Schösler, H., 2016. Transition towards Circular Economy in the Food System. Sustainability 8(1), 69.

Kalmykova, Y., Sadagopan, M., Rosado, L., 2017. Circular economy - From review of theories and practices to development of implementation tools. Resour. Conserv. Recycl. 135, 190-201. 
Kazancoglu, Y., Kazancoglu, I., Sagnak, M., 2018. A new holistic conceptual framework for green supply chain management performance assessment based on circular economy. Journal of Cleaner Production 195, 1282-1299.

Khan, M.A., Mittal, S., West, S., Wuest, T., 2018. Review on upgradability - A product lifetime extension strategy in the context of product service systems. Journal of Cleaner Production 204, 11541168.

King, A.M., Burgess, S.C., ljomah, W., McMahon, C.A., 2006. Reducing waste: repair, recondition, remanufacture or recycle? Sustainable Dev. 14(4), 257-267.

Kjaer, L.L., Pigosso, D.C.A., Niero, M., Bech, N.M., McAloone, T.C., 2018. Product/Service-Systems for a Circular Economy: The Route to Decoupling Economic Growth from Resource Consumption? J. Ind. Ecol.

Krippendorff, K., 2004. Content analysis: An introduction to its methodology. Sage.

Krystofik, M., Luccitti, A., Parnell, K., Thurston, M., 2018. Adaptive remanufacturing for multiple lifecycles: A case study in office furniture. Resour. Conserv. Recycl. 135, 14-23.

Lakatos, E.S., Cioca, L.I., Dan, V., Ciomos, A.O., Crisan, O.A., Barsan, G., 2018. Studies and investigation about the attitude towards sustainable production, consumption and waste generation in line with circular economy in Romania. Sustainability 10(3).

Lapko, Y., Trianni, A., Nuur, C., Masi, D., 2018. In Pursuit of Closed-Loop Supply Chains for Critical Materials: An Exploratory Study in the Green Energy Sector. J. Ind. Ecol.

Larsen, S.B., Masi, D., Jacobsen, P., Godsell, J., 2018. How the reverse supply chain contributes to a firm's competitive strategy: a strategic alignment perspective. Prod Plann Control 29(6), 452-463.

Laso, J., García-Herrero, I., Margallo, M., Vázquez-Rowe, I., Fullana, P., Bala, A., Gazulla, C., Irabien, Á., Aldaco, R., 2018. Finding an economic and environmental balance in value chains based on circular economy thinking: An eco-efficiency methodology applied to the fish canning industry. Resour. Conserv. Recycl. 133, 428-437.

Laurenti, R., Sinha, R., Singh, J., Frostell, B., 2015. Some pervasive challenges to sustainability by design of electronic products - A conceptual discussion. Journal of Cleaner Production 108, 281-288.

Leising, E., Quist, J., Bocken, N., 2018. Circular Economy in the building sector: Three cases and a collaboration tool. Journal of Cleaner Production 176, 976-989.

Leslie, H.A., Leonards, P.E.G., Brandsma, S.H., de Boer, J., Jonkers, N., 2016. Propelling plastics into the circular economy - weeding out the toxics first. Environ. Int. 94, 230-234.

Leszczynska, A., Maryniak, A., 2017. Sustainable supply chain - a review of research fields and a proposition of future exploration. International Journal of Sustainable Economy 9(2), 159-179.

Lewandowski, M., 2016. Designing the business models for circular economy-towards the conceptual framework. Sustainability 8(1), 1-28.

Li, H., Bao, W., Xiu, C., Zhang, Y., Xu, H., 2010. Energy conservation and circular economy in China's process industries. Energy 35(11), 4273-4281. 
Li, Y., Ma, C., 2015. Circular economy of a papermaking park in China: A case study. Journal of Cleaner Production 92, 65-74.

Lieder, M., Asif, F.M.A., Rashid, A., Mihelič, A., Kotnik, S., 2018. A conjoint analysis of circular economy value propositions for consumers: Using "washing machines in Stockholm" as a case study. Journal of Cleaner Production 172, 264-273.

Lieder, M., Rashid, A., 2016. Towards circular economy implementation: a comprehensive review in context of manufacturing industry. Journal of Cleaner Production 115(Supplement C), 36-51.

Linder, M., Sarasini, S., van Loon, P., 2017. A Metric for Quantifying Product-Level Circularity. J. Ind. Ecol. 21(3), 545-558.

Linder, M., Williander, M., 2017. Circular Business Model Innovation: Inherent Uncertainties. Bus. Strategy Environ. 26(2), 182-196.

Liu, J., Feng, Y., Zhu, Q., Sarkis, J., 2018. Green supply chain management and the circular economy: Reviewing theory for advancement of both fields. Int. J. Phys. Distrib. Logist. Manage. 48(8), 794-817. Long, E., Kokke, S., Lundie, D., Shaw, N., ljomah, W., Kao, C.-C., 2016. Technical solutions to improve global sustainable management of waste electrical and electronic equipment (WEEE) in the EU and China. J. Remanuf. 6(1), 1.

Lopes de Sousa Jabbour, A.B., Jabbour, C.J.C., Godinho Filho, M., Roubaud, D., 2018. Industry 4.0 and the circular economy: a proposed research agenda and original roadmap for sustainable operations. Ann. Oper. Res., 1-14.

Low, J.S.C., Ng, Y.T., 2018. Improving the Economic Performance of Remanufacturing Systems through Flexible Design Strategies: A Case Study Based on Remanufacturing Laptop Computers for the Cambodian Market. Bus. Strategy Environ. 27(4), 503-527.

Lüdeke-Freund, F., Gold, S., Bocken, N.M., 2018. A Review and Typology of Circular Economy Business Model Patterns. J. Ind. Ecol.

Malviya, R.K., Ravi, K., 2015. Green supply chain management (GSCM): a structured literature review and research implications. Benchmarking: An International Journal 22(7), 1360-1394.

Mangla, S.K., Luthra, S., Mishra, N., Singh, A., Rana, N.P., Dora, M., Dwivedi, Y., 2018. Barriers to effective circular supply chain management in a developing country context. Prod Plann Control 29(6), 551-569.

Manninen, K., Koskela, S., Antikainen, R., Bocken, N., Dahlbo, H., Aminoff, A., 2018. Do circular economy business models capture intended environmental value propositions? Journal of Cleaner Production 171, 413-422.

Manomaivibool, P., Hong, J.H., 2014. Two decades, three WEEE systems: How far did EPR evolve in Korea's resource circulation policy? Resour. Conserv. Recycl. 83, 202-212.

Mao, Y., Wang, J., 2018. Is green manufacturing expensive? Empirical evidence from China. Int J Prod Res, 1-13.

Marlet, C., 2014. GtoG Life + Project: First step towards gypsum circular economy. ZKG Int. 67(4), 4855. 
Masi, D., Day, S., Godsell, J., 2017. Supply chain configurations in the circular economy: A systematic literature review. Sustainability 9(9).

Masi, D., Kumar, V., Garza-Reyes, J.A., Godsell, J., 2018. Towards a more circular economy: exploring the awareness, practices, and barriers from a focal firm perspective. Prod Plann Control 29(6), 539550 .

Mativenga, P.T., Agwa-Ejon, J., Mbohwa, C., Sultan, A.A.M., Shuaib, N.A., 2017. Circular Economy Ownership Models: A view from South Africa Industry. Procedia Manuf. 8, 284-291.

Mayring, P., 2003. Qualitative inhaltsanalyse [Qualitative content analysis]. Qualitative Forschung 3, 468-475.

Meehan, J., Bryde, D., 2011. Sustainable procurement practice. Bus. Strategy Environ. 20(2), 94-106.

Meho, L.I., Yang, K., 2007. Impact of data sources on citation counts and rankings of LIS faculty: Web of science versus scopus and google scholar. Journal of the American Society for Information Science and Technology 58(13), 2105-2125.

Mendoza, J.M.F., Sharmina, M., Gallego-Schmid, A., Heyes, G., Azapagic, A., 2017. Integrating Backcasting and Eco-Design for the Circular Economy: The BECE Framework. J. Ind. Ecol. 21(3), 526544.

Milios, L., Holm Christensen, L., McKinnon, D., Christensen, C., Rasch, M.K., Hallstrøm Eriksen, M., 2018. Plastic recycling in the Nordics: A value chain market analysis. Waste Management 76, 180-189. Mishra, J.L., Hopkinson, P.G., Tidridge, G., 2018. Value creation from circular economy-led closed loop supply chains: a case study of fast-moving consumer goods. Prod Plann Control 29(6), 509-521.

Mo, H., Wen, Z., Chen, J., 2009. China's recyclable resources recycling system and policy: A case study in Suzhou. Resour. Conserv. Recycl. 53(7), 409-419.

Mohamed Abdul Ghani, N.M.A., Egilmez, G., Kucukvar, M., S. Bhutta, M.K., 2017. From green buildings to green supply chains: An integrated input-output life cycle assessment and optimization framework for carbon footprint reduction policy making. Manage. Environ. Qual. 28(4), 532-548.

Mohanty, A., Misra, M., Hinrichsen, G., 2000. Biofibres, biodegradable polymers and biocomposites: an overview. Macromolecular materials and Engineering 276(1), 1-24.

Moktadir, M.A., Rahman, T., Rahman, M.H., Ali, S.M., Paul, S.K., 2018. Drivers to sustainable manufacturing practices and circular economy: A perspective of leather industries in Bangladesh. Journal of Cleaner Production 174, 1366-1380.

Mongeon, P., Paul-Hus, A., 2016. The journal coverage of Web of Science and Scopus: a comparative analysis. Scientometrics 106(1), 213-228.

Morali, O., Searcy, C., 2013. A Review of Sustainable Supply Chain Management Practices in Canada. J. Bus. Ethics 117(3), 635-658.

Moreno, M., De los Rios, C., Rowe, Z., Charnley, F., 2016. A conceptual framework for circular design. Sustainability 8(9). 
Moula, M.E., Sorvari, J., Oinas, P., 2017. Constructing a green circular society. https://helda.helsinki.fi/bitstream/handle/10138/231630/ebook2017(pdf).pdf?sequence=1. (Accessed 15/03/2018).

Nascimento, D.L.M., Alencastro, V., Quelhas, O.L.G., Caiado, R.G.G., Garza-Reyes, J.A., Lona, L.R., Tortorella, G., 2018. Exploring Industry 4.0 technologies to enable circular economy practices in a manufacturing context: A business model proposal. J. Manuf. Technol. Manage.

Nasir, M.H.A., Genovese, A., Acquaye, A.A., Koh, S.C.L., Yamoah, F., 2017. Comparing linear and circular supply chains: A case study from the construction industry. Int J Prod Econ 183, 443-457.

Niero, M., Olsen, S.I., 2016. Circular economy: To be or not to be in a closed product loop? A Life Cycle Assessment of aluminium cans with inclusion of alloying elements. Resour. Conserv. Recycl. 114, 1831.

Nissinen, A., Parikka-Alhola, K., Rita, H., 2009. Environmental criteria in the public purchases above the EU threshold values by three Nordic countries: 2003 and 2005. Ecol. Econ. 68(6), 1838-1849.

Nowakowski, P., Mrówczyńska, B., 2018. Towards sustainable WEEE collection and transportation methods in circular economy - Comparative study for rural and urban settlements. Resour. Conserv. Recycl. 135, 93-107.

Nußholz, J.L.K., 2017. Circular business models: Defining a concept and framing an emerging research field. Sustainability 9(10).

O'Connor, M.P., Zimmerman, J.B., Anastas, P.T., Plata, D.L., 2016. A strategy for material supply chain sustainability: Enabling a circular economy in the electronics industry through green engineering. ACS Sustainable Chem. Eng. 4(11), 5879-5888.

Oghazi, P., Mostaghel, R., 2018. Circular business model challenges and lessons learned-An industrial perspective. Sustainability 10(3).

Parajuly, K., Wenzel, H., 2017. Potential for circular economy in household WEEE management. Journal of Cleaner Production 151, 272-285.

Park, J., Sarkis, J., Wu, Z., 2010. Creating integrated business and environmental value within the context of China's circular economy and ecological modernization. Journal of Cleaner Production 18(15), 1492-1499.

Peck, D., Kandachar, P., Tempelman, E., 2015. Critical materials from a product design perspective. Mater. Des. 65, 147-159.

Pialot, O., Millet, D., Bisiaux, J., 2017. "Upgradable PSS": Clarifying a new concept of sustainable consumption/production based on upgradablility. Journal of Cleaner Production 141, 538-550.

Polzer, V.R., Pisani, M.A.J., Persson, K.M., 2016. The importance of extended producer responsibility and the national policy of solid waste in Brazil. Int. J. Environ. Waste Manage. 18(2), 101-119.

Popa, V.N., Popa, L.I., 2016. Green Acquisitions And Lifecycle Management Of Industrial Products In The Circular Economy, IOP Conference Series: Materials Science and Engineering. IOP Publishing, p. 012112. 
Poppelaars, F., Bakker, C., van Engelen, J., 2018. Does access trump ownership? Exploring consumer acceptance of access-based consumption in the case of smartphones. Sustainability 10(7).

Preston, F., 2012. A Global Redesign?: Shaping the Circular Economy. Chatham House London.

Ranta, V., Aarikka-Stenroos, L., Ritala, P., Mäkinen, S.J., 2018. Exploring institutional drivers and barriers of the circular economy: A cross-regional comparison of China, the US, and Europe. Resour. Conserv. Recycl. 135, 70-82.

Rathore, P., Kota, S., Chakrabarti, A., 2011. Sustainability through remanufacturing in India: a case study on mobile handsets. Journal of Cleaner Production 19(15), 1709-1722.

Rehman, M.A., Seth, D., Shrivastava, R.L., 2016. Impact of green manufacturing practices on organisational performance in Indian context: An empirical study. Journal of Cleaner Production 137(Supplement C), 427-448.

Rentizelas, A., Shpakova, A., Mašek, O., 2018. Designing an optimised supply network for sustainable conversion of waste agricultural plastics into higher value products. Journal of Cleaner Production 189, 683-700.

Richter, J.L., Koppejan, R., 2016. Extended producer responsibility for lamps in Nordic countries: Best practices and challenges in closing material loops. Journal of Cleaner Production 123, 167-179.

Ridaura, G., Llorens-Cervera, S., Carrillo, C., Buj-Corral, I., Riba-Romeva, C., 2018. Equipment suppliers integration to the redesign for emissions reuse in industrial processes. Resour. Conserv. Recycl. 131, 75-85.

Rizos, V., Behrens, A., van der Gaast, W., Hofman, E., loannou, A., Kafyeke, T., Flamos, A., Rinaldi, R., Papadelis, S., Hirschnitz-Garbers, M., Topi, C., 2016. Implementation of circular economy business models by small and medium-sized enterprises (SMEs): Barriers and enablers. Sustainability 8(11).

Roos, G., 2014. Business model innovation to create and capture resource value in future circular material chains. Resources 3(1), 248-274.

Sabaghi, M., Mascle, C., Baptiste, P., 2016. Evaluation of products at design phase for an efficient disassembly at end-of-life. Journal of Cleaner Production 116, 177-186.

Salemdeeb, R., Al-Tabbaa, A., Reynolds, C., 2016. The UK waste input-output table: Linking waste generation to the UK economy. Waste Manage. Res. 34(10), 1089-1094.

Sbihi, A., Eglese, R.W., 2010. Combinatorial optimization and Green Logistics. Ann. Oper. Res. 175(1), 159-175.

Scheel, C., Vasquez, M., 2013. Regional wealth creation by leveraging residues and waste. Vie \& sciences de l'entreprise(2), 72-92.

Scheel, C., Vazquez, M., 2011. The role of innovation and technology in industrial ecology systems for the sustainable development of emerging regions. Journal of sustainable development 4(6), 197.

Seman, N.A.A., Zakuan, N., Jusoh, A., Arif, M.S.M., Saman, M.Z.M., 2012. Green supply chain management: a review and research direction. International Journal of Managing Value and supply chains 3(1), 1-18. 
Seuring, S., Müller, M., 2008. From a literature review to a conceptual framework for sustainable supply chain management. Journal of Cleaner Production 16(15), 1699-1710.

Shahbazi, S., Wiktorsson, M., Kurdve, M., Jönsson, C., Bjelkemyr, M., 2016. Material efficiency in manufacturing: swedish evidence on potential, barriers and strategies. Journal of Cleaner Production $127,438-450$.

Sharma, V., Garg, S.K., Sharma, P.B., 2016. Identification of major drivers and roadblocks for remanufacturing in India. Journal of Cleaner Production 112(Part 3), 1882-1892.

Sihvonen, S., Partanen, J., 2018. A survey of perceived prevalence of selected environmental topics in product development, and their relationships with employee's ecological concern. Journal of Cleaner Production 199, 1116-1129.

Singh, J., Ordoñez, I., 2016. Resource recovery from post-consumer waste: important lessons for the upcoming circular economy. Journal of Cleaner Production 134, 342-353.

Singh, P., Giacosa, E., 2018. Cognitive biases of consumers as barriers in transition towards circular economy. Manage. Decis.

Sousa-Zomer, T.T., Magalhães, L., Zancul, E., Campos, L.M.S., Cauchick-Miguel, P.A., 2018a. Cleaner production as an antecedent for circular economy paradigm shift at the micro-level: Evidence from a home appliance manufacturer. Journal of Cleaner Production 185, 740-748.

Sousa-Zomer, T.T., Magalhães, L., Zancul, E., Cauchick-Miguel, P.A., 2018b. Exploring the challenges for circular business implementation in manufacturing companies: An empirical investigation of a payper-use service provider. Resour. Conserv. Recycl. 135, 3-13.

Souza, G.C., 2013. Closed-Loop Supply Chains: A Critical Review, and Future Research. Decision Sciences 44(1), 7-38.

Sprecher, B., Daigo, I., Spekkink, W., Vos, M., Kleijn, R., Murakami, S., Kramer, G.J., 2017. Novel Indicators for the Quantification of Resilience in Critical Material Supply Chains, with a 2010 Rare Earth Crisis Case Study. Environ. Sci. Technol. 51(7), 3860-3870.

Spring, M., Araujo, L., 2017. Product biographies in servitization and the circular economy. Ind. Mark. Manage. 60, 126-137.

Srivastava, S.K., 2007. Green supply-chain management: A state-of-the-art literature review. International Journal of Management Reviews 9(1), 53-80.

Stahel, W., 2010. The performance economy. Springer.

Steenis, N.D., van der Lans, I.A., van Herpen, E., van Trijp, H.C.M., 2018. Effects of sustainable design strategies on consumer preferences for redesigned packaging. Journal of Cleaner Production 205, 854865.

Stewart, R., Niero, M., 2018. Circular economy in corporate sustainability strategies: A review of corporate sustainability reports in the fast-moving consumer goods sector. Bus. Strategy Environ. 27(7), 1005-1022.

Su, B., Heshmati, A., Geng, Y., Yu, X., 2013. A review of the circular economy in China: moving from rhetoric to implementation. Journal of Cleaner Production 42(Supplement C), 215-227. 
Sumter, D., Bakker, C., Balkenende, R., 2018. The role of product design in creating circular business models: A case study on the lease and refurbishment of baby strollers. Sustainability 10(7).

Sun, Q., 2017. Research on the influencing factors of reverse logistics carbon footprint under sustainable development. Environ. Sci. Pollut. Res. 24(29), 22790-22798.

Tajik, S., Maghsoudlou, Y., Khodaiyan, F., Jafari, S.M., Ghasemlou, M., Aalami, M., 2013. Soluble soybean polysaccharide: A new carbohydrate to make a biodegradable film for sustainable green packaging. Carbohydrate Polymers 97(2), 817-824.

Talens Peiró, L., Ardente, F., Mathieux, F., 2017. Design for Disassembly Criteria in EU Product Policies for a More Circular Economy: A Method for Analyzing Battery Packs in PC-Tablets and Subnotebooks. J. Ind. Ecol. 21(3), 731-741.

Tarantini, M., Loprieno, A.D., Porta, P.L., 2011. A life cycle approach to Green Public Procurement of building materials and elements: A case study on windows. Energy 36(5), 2473-2482.

Tian, J., Chen, M., 2014. Sustainable design for automotive products: Dismantling and recycling of endof-life vehicles. Waste Management 34(2), 458-467.

Toffel, M.W., 2004. Strategic Management of Product Recovery. California Management Review 46(2), 120-141.

Tukker, A., 2015. Product services for a resource-efficient and circular economy - A review. Journal of Cleaner Production 97, 76-91.

Urbinati, A., Chiaroni, D., Chiesa, V., 2017. Towards a new taxonomy of circular economy business models. Journal of Cleaner Production 168, 487-498.

van Loon, P., Delagarde, C., Van Wassenhove, L.N., 2017. The role of second-hand markets in circular business: a simple model for leasing versus selling consumer products. Int J Prod Res, 1-14.

van Loon, P., Van Wassenhove, L.N., 2017. Assessing the economic and environmental impact of remanufacturing: a decision support tool for OEM suppliers. Int J Prod Res, 1-13.

van Weelden, E., Mugge, R., Bakker, C., 2016. Paving the way towards circular consumption: Exploring consumer acceptance of refurbished mobile phones in the Dutch market. Journal of Cleaner Production 113, 743-754.

Vanegas, P., Peeters, J.R., Cattrysse, D., Tecchio, P., Ardente, F., Mathieux, F., Dewulf, W., Duflou, J.R., 2018. Ease of disassembly of products to support circular economy strategies. Resour. Conserv. Recycl. $135,323-334$.

Vasantha, G.V.A., Roy, R., Corney, J.R., 2015. Advances in Designing Product-Service Systems. J Indian Inst Sci 95(4), 429-447.

Veleva, V., Bodkin, G., 2017. Emerging drivers and business models for equipment reuse and remanufacturing in the US: lessons from the biotech industry. J. Environ. Plann. Manage., 1-23.

Vlajic, J.V., Mijailovic, R., Bogdanova, M., 2018. Creating loops with value recovery: empirical study of fresh food supply chains. Prod Plann Control 29(6), 522-538.

Wang, P., Kuah, A.T.H., 2018. Green marketing cradle-to-cradle: Remanufactured products in Asian markets. Thunderbird Int. Bus. Rev. 60(5), 783-795. 
Wang, Y., Hazen, B.T., 2016. Consumer product knowledge and intention to purchase remanufactured products. Int J Prod Econ 181, 460-469.

Weetman, C., 2017. A Circular Economy Handbook for Business and Supply Chains: Repair, Remake, Redesign, Rethink. Kogan Page.

Whalen, K.A., Milios, L., Nussholz, J., 2018. Bridging the gap: Barriers and potential for scaling reuse practices in the Swedish ICT sector. Resour. Conserv. Recycl. 135, 123-131.

Wieser, H., Tröger, N., 2016. Exploring the inner loops of the circular economy: Replacement, repair, and reuse of mobile phones in Austria. Journal of Cleaner Production 172, 3042-3055.

Winans, K., Kendall, A., Deng, H., 2017. The history and current applications of the circular economy concept. Renewable Sustainable Energy Rev 68, 825-833.

Winkler, H., 2011. Closed-loop production systems-A sustainable supply chain approach. CIRP J. Manuf. Sci. Technol. 4(3), 243-246.

Winkler, H., Kaluza, B., 2006. Sustainable supply chain networks - A new approach for effective waste management. WIT Transactions on Ecology and the Environment 92, 501-510.

Witjes, S., Lozano, R., 2016. Towards a more Circular Economy: Proposing a framework linking sustainable public procurement and sustainable business models. Resour. Conserv. Recycl. 112, 3744.

Wübbeke, J., Heroth, T., 2014. Challenges and political solutions for steel recycling in China. Resour. Conserv. Recycl. 87, 1-7.

Xue, H.y., Yang, D.h., 2010. Implementing Circular Consumption by Means of Second-Hand Goods Market, 2010 International Conference on Management and Service Science. pp. 1-4.

Yang, M., Smart, P., Kumar, M., Jolly, M., Evans, S., 2018. Product-service systems business models for circular supply chains. Prod Plann Control 29(6), 498-508.

Ying, J., Li-jun, Z., 2012. Study on Green Supply Chain Management Based on Circular Economy. Physics Procedia 25(Supplement C), 1682-1688.

Zhang, G., Zhao, Z., 2012. Green Packaging Management of Logistics Enterprises. Physics Procedia 24(Part B), 900-905.

Zhang, J.H., Chen, M., 2015. Assessing the impact of China's vehicle emission standards on diesel engine remanufacturing. Journal of Cleaner Production 107, 177-184.

Zhang, T., Chu, J., Wang, X., Liu, X., Cui, P., 2011. Development pattern and enhancing system of automotive components remanufacturing industry in China. Resources, Conservation and Recycling 55(6), 613-622.

Zhang, T., Wang, X., Chu, J., Liu, X., Cui, P., 2010. Automotive recycling information management based on the internet of things and RFID technology, Advanced Management Science (ICAMS), 2010 IEEE International Conference on. IEEE, pp. 620-622.

Zhong, S., Pearce, J.M., 2018. Tightening the loop on the circular economy: Coupled distributed recycling and manufacturing with recyclebot and RepRap 3-D printing. Resour. Conserv. Recycl. 128, $48-58$ 
Zhou, M., Pan, Y., Chen, Z., Yang, W., Li, B., 2012. Selection and evaluation of green production strategies: analytic and simulation models. Journal of Cleaner Production 26(Supplement C), 9-17.

Zhu, Q., Geng, Y., Lai, K.H., 2010. Circular economy practices among Chinese manufacturers varying in environmental-oriented supply chain cooperation and the performance implications. Journal of Environmental Management 91(6), 1324-1331.

Zhu, Q., Geng, Y., Lai, K.H., 2011. Environmental supply chain cooperation and its effect on the circular economy practice-performance relationship among Chinese manufacturers. J. Ind. Ecol. 15(3), 405419. 


\section{Classification of literature on CSCM}

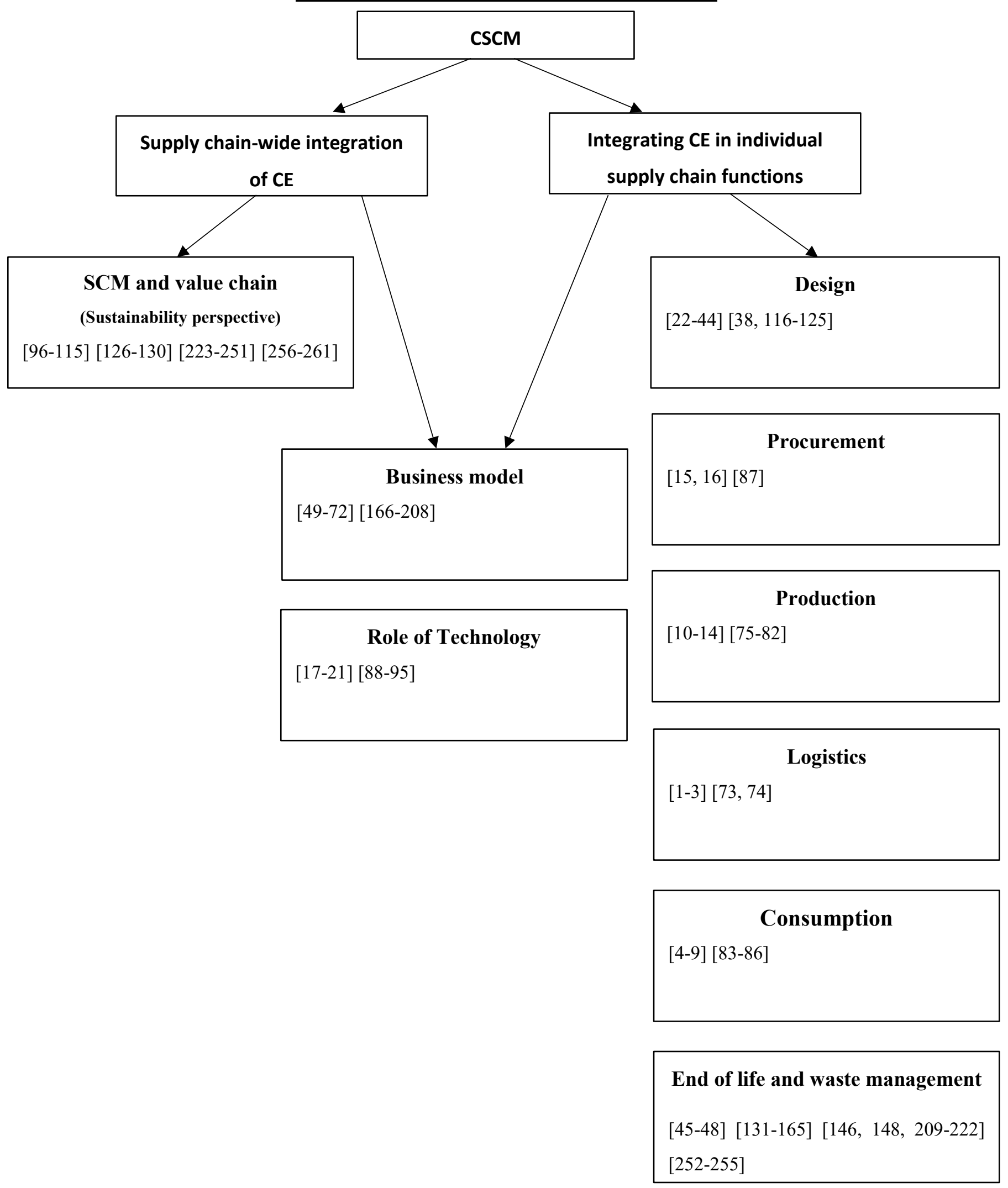


1. Dhakal, M., M.H. Smith, and R. Newbery, Secondary market: A significant aspect in reverse logistics and sustainability. International Journal of Sustainability in Economic, Social, and Cultural Context, 2016. 12(1): p. 24-35.

2. Sun, Q., Research on the influencing factors of reverse logistics carbon footprint under sustainable development. Environmental Science and Pollution Research, 2017. 24(29): p. 22790-22798.

3. Dente, S.M.R. and L.A. Tavasszy, Impacts of trade related sustainability strategies on freight transportation: Modelling framework and application for France. Transportation Research Part D: Transport and Environment, 2017.

4. Jurgilevich, A., et al., Transition towards Circular Economy in the Food System. Sustainability, 2016. 8(1): p. 69.

5. Canning, L., Rethinking market connections: mobile phone recovery, reuse and recycling in the UK. Journal of Business \& Industrial Marketing, 2006. 21(5): p. 320-329.

6. van Weelden, E., R. Mugge, and C. Bakker, Paving the way towards circular consumption: Exploring consumer acceptance of refurbished mobile phones in the Dutch market. Journal of Cleaner Production, 2016. 113: $p$. 743-754.

7. Wieser, H. and N. Tröger, Exploring the inner loops of the circular economy: Replacement, repair, and reuse of mobile phones in Austria. Journal of Cleaner Production, 2016. 172: p. 3042-3055.

8. Wang, Y. and B.T. Hazen, Consumer product knowledge and intention to purchase remanufactured products. International Journal of Production Economics, 2016. 181: p. 460-469.

9. Castellani, V., S. Sala, and N. Mirabella, Beyond the throwaway society: A life cycle-based assessment of the environmental benefit of reuse. Integrated Environmental Assessment and Management, 2015. 11(3): p. 373382.

10. Leslie, H.A., et al., Propelling plastics into the circular economy - weeding out the toxics first. Environment International, 2016. 94: p. 230-234.

11. Shahbazi, S., et al., Material efficiency in manufacturing: swedish evidence on potential, barriers and strategies. Journal of Cleaner Production, 2016. 127: p. 438-450.

12. Antoniou, N. and A. Zabaniotou, Experimental proof of concept for a sustainable End of Life Tyres pyrolysis with energy and porous materials production. Journal of Cleaner Production, 2015. 101: p. 1-14.

13. Li, Y. and C. Ma, Circular economy of a papermaking park in China: A case study. Journal of Cleaner Production, 2015. 92: p. 65-74.

14. Low, J.S.C., et al., Adaptation of the Product Structure-based Integrated Life cycle Analysis (PSILA) technique for carbon footprint modelling and analysis of closed-loop production systems. Journal of Cleaner Production, 2016. 120: p. 105-123.

15. Witjes, S. and R. Lozano, Towards a more Circular Economy: Proposing a framework linking sustainable public procurement and sustainable business models. Resources, Conservation and Recycling, 2016. 112: p. 37-44.

16. Sprecher, B., et al., Novel Indicators for the Quantification of Resilience in Critical Material Supply Chains, with a 2010 Rare Earth Crisis Case Study. Environmental Science and Technology, 2017. 51(7): p. 3860-3870.

17. Cong, L., F. Zhao, and J.W. Sutherland, Value recovery from end-of-use products facilitated by automated dismantling planning. Clean Technologies and Environmental Policy, 2017. 19(7): p. 1867-1882. 
18. Despeisse, M., et al., Unlocking value for a circular economy through 3D printing: A research agenda. Technological Forecasting and Social Change, 2017. 115: p. 75-84.

19. Jabbour, C.J.C., et al., Unlocking the circular economy through new business models based on large-scale data: An integrative framework and research agenda. Technological Forecasting and Social Change, 2017.

20. Alvarez-de-los-Mozos, E. and A. Renteria, Collaborative Robots in e-waste Management. Procedia Manufacturing, 2017. 11: p. 55-62.

21. Giurco, D., et al., Circular economy: Questions for responsible minerals, additive manufacturing and recycling of metals. Resources, 2014. 3(2): p. 432-453.

22. Kane, G.M., C.A. Bakker, and A.R. Balkenende, Towards design strategies for circular medical products. Resources, Conservation and Recycling, 2018. 135: p. 38-47.

23. Lieder, M., et al., Towards circular economy implementation in manufacturing systems using a multi-method simulation approach to link design and business strategy. International Journal of Advanced Manufacturing Technology, 2017. 93(5-8): p. 1953-1970.

24. Tian, J. and M. Chen, Sustainable design for automotive products: Dismantling and recycling of end-of-life vehicles. Waste Management, 2014. 34(2): p. 458-467.

25. Broadbent, C., Steel's recyclability: demonstrating the benefits of recycling steel to achieve a circular economy. International Journal of Life Cycle Assessment, 2016. 21(11): p. 1658-1665.

26. Laurenti, R., et al., Some pervasive challenges to sustainability by design of electronic products - A conceptual discussion. Journal of Cleaner Production, 2015. 108: p. 281-288.

27. De los Rios, I.C. and F.J.S. Charnley, Skills and capabilities for a sustainable and circular economy: The changing role of design. Journal of Cleaner Production, 2017. 160: p. 109-122.

28. Bakker, C., et al., Products that go round: Exploring product life extension through design. Journal of Cleaner Production, 2014. 69: p. 10-16.

29. den Hollander, M.C., C.A. Bakker, and E.J. Hultink, Product Design in a Circular Economy: Development of a Typology of Key Concepts and Terms. Journal of Industrial Ecology, 2017. 21(3): p. 517-525.

30. Bocken, N.M.P., et al., Product design and business model strategies for a circular economy. Journal of Industrial and Production Engineering, 2016. 33(5): p. 308-320.

31. Dalhammar, C., Industry attitudes towards ecodesign standards for improved resource efficiency. Journal of Cleaner Production, 2016. 123: p. 155-166.

32. Whalen, K. and D. Peck, In the loop - Sustainable, circular product design and critical materials. International Journal of Automation Technology, 2014. 8(5): p. 664-676.

33. Tecchio, P., et al., In search of standards to support circularity in product policies: A systematic approach. Journal of Cleaner Production, 2017. 168: p. 1533-1546.

34. Sihvonen, S. and J. Partanen, Implementing environmental considerations within product development practices: A survey on employees' perspectives. Journal of Cleaner Production, 2016. 125: p. 189-203.

35. Bundgaard, A.M., M.A. Mosgaard, and A. Remmen, From energy efficiency towards resource efficiency within the Ecodesign Directive. Journal of Cleaner Production, 2017. 144: p. 358-374. 
36. Sabaghi, M., C. Mascle, and P. Baptiste, Evaluation of products at design phase for an efficient disassembly at end-of-life. Journal of Cleaner Production, 2016.

37. Sihvonen, S. and J. Partanen, Eco-design practices with a focus on quantitative environmental targets: An exploratory content analysis within ICT sector. Journal of Cleaner Production, 2017. 143: p. 769-783.

38. Vanegas, P., et al., Ease of disassembly of products to support circular economy strategies. Resources, Conservation and Recycling, 2018. 135: p. 323-334.

39. Cayzer, S., P. Griffiths, and V. Beghetto, Design of indicators for measuring product performance in the circular economy. International Journal of Sustainable Engineering, 2017. 10(4-5): p. 289-298.

40. Talens Peiró, L., F. Ardente, and F. Mathieux, Design for Disassembly Criteria in EU Product Policies for a More Circular Economy: A Method for Analyzing Battery Packs in PC-Tablets and Subnotebooks. Journal of Industrial Ecology, 2017. 21(3): p. 731-741.

41. Peck, D., P. Kandachar, and E. Tempelman, Critical materials from a product design perspective. Materials and Design, 2015. 65: p. 147-159.

42. Moreno, M., et al., A conceptual framework for circular design. Sustainability (Switzerland), 2016. 8(9).

43. Andrews, D., The circular economy, design thinking and education for sustainability. Local Economy, 2015. 30(3): p. 305-315.

44. Clark, J.H., et al., Circular economy design considerations for research and process development in the chemical sciences. Green Chemistry, 2016. 18(14): p. 3914-3934.

45. Tong, X., et al., Towards an inclusive circular economy: Quantifying the spatial flows of e-waste through the informal sector in China. Resources, Conservation and Recycling, 2018. 135: p. 163-171.

46. Singh, J. and I. Ordoñez, Resource recovery from post-consumer waste: important lessons for the upcoming circular economy. Journal of Cleaner Production, 2016. 134: p. 342-353.

47. Işıldar, A., et al., Electronic waste as a secondary source of critical metals: Management and recovery technologies. Resources, Conservation and Recycling, 2018. 135: p. 296-312.

48. Richa, K., C.W. Babbitt, and G. Gaustad, Eco-Efficiency Analysis of a Lithium-Ion Battery Waste Hierarchy Inspired by Circular Economy. Journal of Industrial Ecology, 2017. 21(3): p. 715-730.

49. Pialot, O., D. Millet, and J. Bisiaux, "Upgradable PSS": Clarifying a new concept of sustainable consumption/production based on upgradablility. Journal of Cleaner Production, 2017. 141: p. 538-550.

50. Scheepens, A.E., J.G. Vogtländer, and J.C. Brezet, Two life cycle assessment (LCA) based methods to analyse and design complex (regional) circular economy systems. Case: Making water tourism more sustainable. Journal of Cleaner Production, 2016. 114: p. 257-268.

51. Gorissen, L., K. Vrancken, and S. Manshoven, Transition thinking and business model innovation-towards a transformative business model and new role for the reuse centers of Limburg, Belgium. Sustainability (Switzerland), 2016. 8(2).

52. Lieder, M., F.M.A. Asif, and A. Rashid, Towards Circular Economy implementation: an agent-based simulation approach for business model changes. Autonomous Agents and Multi-Agent Systems, 2017. 31(6): p. 13771402. 
53. Urbinati, A., D. Chiaroni, and V. Chiesa, Towards a new taxonomy of circular economy business models. Journal of Cleaner Production, 2017. 168: p. 487-498.

54. Stål, H.I. and J. Jansson, Sustainable Consumption and Value Propositions: Exploring Product-Service System Practices Among Swedish Fashion Firms. Sustainable Development, 2017. 25(6): p. 546-558.

55. Tukker, A., Product services for a resource-efficient and circular economy - A review. Journal of Cleaner Production, 2015. 97: p. 76-91.

56. Spring, M. and L. Araujo, Product biographies in servitization and the circular economy. Industrial Marketing Management, 2017. 60: p. 126-137.

57. Schulte, U.G., New business models for a radical change in resource efficiency. Environmental Innovation and Societal Transitions, 2013. 9: p. 43-47.

58. Mendoza, J.M.F., et al., Integrating Backcasting and Eco-Design for the Circular Economy: The BECE Framework. Journal of Industrial Ecology, 2017. 21(3): p. 526-544.

59. Todeschini, B.V., et al., Innovative and sustainable business models in the fashion industry: Entrepreneurial drivers, opportunities, and challenges. Business Horizons, 2017. 60(6): p. 759-770.

60. Rizos, V., et al., Implementation of circular economy business models by small and medium-sized enterprises (SMEs): Barriers and enablers. Sustainability (Switzerland), 2016. 8(11).

61. Lakatos, E.S., et al., How supportive are Romanian consumers of the circular economy concept: A survey. Sustainability (Switzerland), 2016. 8(8).

62. Lewandowski, M., Designing the business models for circular economy-towards the conceptual framework. Sustainability (Switzerland), 2016. 8(1): p. 1-28.

63. Niero, M., et al., Combining Eco-Efficiency and Eco-Effectiveness for Continuous Loop Beverage Packaging Systems: Lessons from the Carlsberg Circular Community. Journal of Industrial Ecology, 2017. 21(3): p. 742753.

64. Vogtlander, J.G., et al., Combined analyses of costs, market value and eco-costs in circular business models: eco-efficient value creation in remanufacturing. Journal of Remanufacturing, 2017. 7(1).

65. Hobson, K., Closing the loop or squaring the circle? Locating generative spaces for the circular economy. Progress in Human Geography, 2016. 40(1): p. 88-104.

66. Mativenga, P.T., et al., Circular Economy Ownership Models: A view from South Africa Industry. Procedia Manufacturing, 2017. 8: p. 284-291.

67. Nußholz, J.L.K., Circular business models: Defining a concept and framing an emerging research field. Sustainability (Switzerland), 2017. 9(10).

68. Linder, M. and M. Williander, Circular Business Model Innovation: Inherent Uncertainties. Business Strategy and the Environment, 2017. 26(2): p. 182-196.

69. Roos, G., Business model innovation to create and capture resource value in future circular material chains. Resources, 2014. 3(1): p. 248-274.

70. Bocken, N.M.P., et al., Business model experimentation for circularity: Driving sustainability in a large international clothing retailer. Economics and Policy of Energy and the Environment, 2017. 2017(1): p. 85-122. 
71. Whalen, K.A., L. Milios, and J. Nussholz, Bridging the gap: Barriers and potential for scaling reuse practices in the Swedish ICT sector. Resources, Conservation and Recycling, 2018. 135: p. 123-131.

72. Vasantha, G.V.A., R. Roy, and J.R. Corney, Advances in Designing Product-Service Systems. Journal of the Indian Institute of Science, 2015. 95(4): p. 429-447.

73. Esposito, M., T. Tse, and K. Soufani, Reverse logistics for postal services within a circular economy. Thunderbird International Business Review, 2018. 60(5): p. 741-745.

74. Bernon, M., B. Tjahjono, and E.F. Ripanti, Aligning retail reverse logistics practice with circular economy values: an exploratory framework. Production Planning and Control, 2018. 29(6): p. 483-497.

75. Wang, P., S. Kara, and M.Z. Hauschild, Role of manufacturing towards achieving circular economy: The steel case. CIRP Annals, 2018. 67(1): p. 21-24.

76. Casarejos, F., et al., Rethinking packaging production and consumption vis-à-vis circular economy: A case study of compostable cassava starch-based material. Journal of Cleaner Production, 2018. 201: p. 1019-1028.

77. Mao, Y. and J. Wang, Is green manufacturing expensive? Empirical evidence from China. International Journal of Production Research, 2018: p. 1-13.

78. Ghisellini, P., et al., Evaluating the transition towards cleaner production in the construction and demolition sector of China: A review. Journal of Cleaner Production, 2018. 195: p. 418-434.

79. Ridaura, G., et al., Equipment suppliers integration to the redesign for emissions reuse in industrial processes. Resources, Conservation and Recycling, 2018. 131: p. 75-85.

80. Moktadir, M.A., et al., Drivers to sustainable manufacturing practices and circular economy: A perspective of leather industries in Bangladesh. Journal of Cleaner Production, 2018. 174: p. 1366-1380.

81. Sousa-Zomer, T.T., et al., Cleaner production as an antecedent for circular economy paradigm shift at the micro-level: Evidence from a home appliance manufacturer. Journal of Cleaner Production, 2018. 185: p. 740748.

82. Vimal, K.E.K., S. Rajak, and J. Kandasamy, Analysis of network design for a circular production system using multi-objective mixed integer linear programming model. Journal of Manufacturing Technology Management, 2018.

83. Gaur, J., et al., Towards building circular economy: A cross-cultural study of consumers' purchase intentions for reconstructed products. Management Decision, 2018.

84. Lakatos, E.S., et al., Studies and investigation about the attitude towards sustainable production, consumption and waste generation in line with circular economy in Romania. Sustainability (Switzerland), 2018. 10(3).

85. Junnila, S., J. Ottelin, and L. Leinikka, Influence of reduced ownership on the environmental benefits of the circular economy. Sustainability (Switzerland), 2018. 10(11).

86. Camacho-Otero, J., C. Boks, and I.N. Pettersen, Consumption in the circular economy: A literature review. Sustainability (Switzerland), 2018. 10(8).

87. Gaustad, G., et al., Circular economy strategies for mitigating critical material supply issues. Resources, Conservation and Recycling, 2018. 135: p. 24-33. 
88. Zhong, S. and J.M. Pearce, Tightening the loop on the circular economy: Coupled distributed recycling and manufacturing with recyclebot and RepRap 3-D printing. Resources, Conservation and Recycling, 2018. 128: $p$. 48-58.

89. Yang, S., et al., Opportunities for industry 4.0 to support remanufacturing. Applied Sciences (Switzerland), 2018. 8(7).

90. Lopes de Sousa Jabbour, A.B., et al., Industry 4.0 and the circular economy: a proposed research agenda and original roadmap for sustainable operations. Annals of Operations Research, 2018. 270(1-2): p. 273-286.

91. Rajala, R., et al., How Do Intelligent Goods Shape Closed-Loop Systems? California Management Review, 2018. 60(3): p. 20-44.

92. Esmaeilian, B., et al., The future of waste management in smart and sustainable cities: A review and concept paper. Waste Management, 2018. 81: p. 177-195.

93. Nascimento, D.L.M., et al., Exploring Industry 4.0 technologies to enable circular economy practices in a manufacturing context: A business model proposal. Journal of Manufacturing Technology Management, 2018.

94. Bressanelli, G., et al., Exploring how usage-focused business models enable circular economy through digital technologies. Sustainability (Switzerland), 2018. 10(3).

95. Garmulewicz, A., et al., Disruptive Technology as an Enabler of the Circular Economy: What Potential Does 3D Printing Hold? California Management Review, 2018.

96. Bodova, E., Tools of environmental management and EU circular economy. MM Science Journal, 2017. 2017(FEBRUARY): p. 1700-1706.

97. Winkler, H. and B. Kaluza, Sustainable supply chain networks - A new approach for effective waste management. WIT Transactions on Ecology and the Environment, 2006. 92: p. 501-510.

98. Genovese, A., et al., Sustainable supply chain management and the transition towards a circular economy: Evidence and some applications. Omega (United Kingdom), 2017. 66: p. 344-357.

99. Masi, D., S. Day, and J. Godsell, Supply chain configurations in the circular economy: A systematic literature review. Sustainability (Switzerland), 2017. 9(9).

100. O'Connor, M.P., et al., A strategy for material supply chain sustainability: Enabling a circular economy in the electronics industry through green engineering. ACS Sustainable Chemistry and Engineering, 2016. 4(11): p. 5879-5888.

101. Pan, S.Y., et al., Strategies on implementation of waste-to-energy (WTE) supply chain for circular economy system: A review. Journal of Cleaner Production, 2014. 108.

102. Ghisellini, P., C. Cialani, and S. Ulgiati, A review on circular economy: The expected transition to a balanced interplay of environmental and economic systems. Journal of Cleaner Production, 2016. 114: p. 11-32.

103. Accorsi, R., et al., On the design of closed-loop networks for product life cycle management: Economic, environmental and geography considerations. Journal of Transport Geography, 2015. 48: p. 121-134.

104. Di Maio, F., et al., Measuring resource efficiency and circular economy: A market value approach. Resources, Conservation and Recycling, 2017. 122: p. 163-171.

105. Zeng, H., et al., Institutional pressures, sustainable supply chain management, and circular economy capability: Empirical evidence from Chinese eco-industrial park firms. Journal of Cleaner Production, 2017. 155: p. 54-65. 
106. Clark, J.H., From waste to wealth using green chemistry: The way to long term stability. Current Opinion in Green and Sustainable Chemistry, 2017. 8: p. 10-13.

107. Mohamed Abdul Ghani, N.M.A., et al., From green buildings to green supply chains: An integrated input-output life cycle assessment and optimization framework for carbon footprint reduction policy making. Management of Environmental Quality: An International Journal, 2017. 28(4): p. 532-548.

108. Zhu, Q., Y. Geng, and K.H. Lai, Environmental supply chain cooperation and its effect on the circular economy practice-performance relationship among Chinese manufacturers. Journal of Industrial Ecology, 2011. 15(3): p. 405-419.

109. Park, J., J. Sarkis, and Z. Wu, Creating integrated business and environmental value within the context of China's circular economy and ecological modernization. Journal of Cleaner Production, 2010. 18(15): p. 1492-1499.

110. Borrello, M., et al., Consumers' perspective on circular economy strategy for reducing food waste. Sustainability (Switzerland), 2017. 9(1).

111. Nasir, M.H.A., et al., Comparing linear and circular supply chains: A case study from the construction industry. International Journal of Production Economics, 2017. 183: p. 443-457.

112. Winkler, H., Closed-loop production systems-A sustainable supply chain approach. CIRP Journal of Manufacturing Science and Technology, 2011. 4(3): p. 243-246.

113. Zhu, Q., Y. Geng, and K.H. Lai, Circular economy practices among Chinese manufacturers varying in environmental-oriented supply chain cooperation and the performance implications. Journal of Environmental Management, 2010. 91(6): p. 1324-1331.

114. Franco, M.A., Circular economy at the micro level: A dynamic view of incumbents' struggles and challenges in the textile industry. Journal of Cleaner Production, 2017. 168: p. 833-845.

115. Jiliang, Z. and Z. Chen, Building and application of a circular economy index system frame for manufacturing industrial chain. Research Journal of Applied Sciences, Engineering and Technology, 2013. 5(24): p. 8646-8651.

116. Sihvonen, S. and J. Partanen, A survey of perceived prevalence of selected environmental topics in product development, and their relationships with employee's ecological concern. Journal of Cleaner Production, 2018. 199: p. 1116-1129.

117. Subramanian, N., et al., Role of traditional Chinese philosophies and new product development under circular economy in private manufacturing enterprise performance. International Journal of Production Research, 2018.

118. Sumter, D., C. Bakker, and R. Balkenende, The role of product design in creating circular business models: $A$ case study on the lease and refurbishment of baby strollers. Sustainability (Switzerland), 2018. 10(7).

119. Pinheiro, M.A.P., et al., The role of new product development in underpinning the circular economy: $A$ systematic review and integrative framework. Management Decision, 2018.

120. Bovea, M.D., et al., Options for labelling circular products: Icon design and consumer preferences. Journal of Cleaner Production, 2018. 202: p. 1253-1263.

121. Bovea, M.D., et al., Incorporation of circular aspects into product design and labelling: Consumer preferences. Sustainability (Switzerland), 2018. 10(7). 
122. Bovea, M.D. and V. Pérez-Belis, Identifying design guidelines to meet the circular economy principles: A case study on electric and electronic equipment. Journal of Environmental Management, 2018. 228: p. 483-494.

123. Lofthouse, V. and S. Prendeville, Human-Centred Design of Products And Services for the Circular Economy-A Review. Design Journal, 2018: p. 1-26.

124. Haines-Gadd, M., et al., Emotional durability design Nine-A tool for product longevity. Sustainability (Switzerland), 2018. 10(6).

125. Steenis, N.D., et al., Effects of sustainable design strategies on consumer preferences for redesigned packaging. Journal of Cleaner Production, 2018. 205: p. 854-865.

126. Golev, A. and G.D. Corder, Quantifying metal values in e-waste in Australia: The value chain perspective. Minerals Engineering, 2017. 107: p. 81-87.

127. Linder, M., S. Sarasini, and P. van Loon, A Metric for Quantifying Product-Level Circularity. Journal of Industrial Ecology, 2017. 21(3): p. 545-558.

128. Winans, K., A. Kendall, and H. Deng, The history and current applications of the circular economy concept. Renewable and Sustainable Energy Reviews, 2017. 68: p. 825-833.

129. Kalmykova, Y., M. Sadagopan, and L. Rosado, Circular economy - From review of theories and practices to development of implementation tools. Resources, Conservation and Recycling, 2017. 135: p. 190-201.

130. Scheel, C., Beyond sustainability. Transforming industrial zero-valued residues into increasing economic returns. Journal of Cleaner Production, 2016. 131: p. 376-386.

131. Densley Tingley, D., S. Cooper, and J. Cullen, Understanding and overcoming the barriers to structural steel reuse, a UK perspective. Journal of Cleaner Production, 2017. 148: p. 642-652.

132. Salemdeeb, R., A. Al-Tabbaa, and C. Reynolds, The UK waste input-output table: Linking waste generation to the UK economy. Waste Management and Research, 2016. 34(10): p. 1089-1094.

133. Golev, A. and G.D. Corder, Typology of options for metal recycling: Australia's perspective. Resources, 2016. 5(1).

134. Krystofik, M. and G. Gaustad, Tying product reuse into tying arrangements to achieve competitive advantage and environmental improvement. Resources, Conservation and Recycling, 2018. 135: p. 235-245.

135. Manomaivibool, P. and J.H. Hong, Two decades, three WEEE systems: How far did EPR evolve in Korea's resource circulation policy? Resources, Conservation and Recycling, 2014. 83: p. 202-212.

136. Gu, Y., et al., To realize better extended producer responsibility: Redesign of WEEE fund mode in China. Journal of Cleaner Production, 2017. 164: p. 347-356.

137. Diener, D.L. and A.M. Tillman, Scrapping steel components for recycling - Isn't that good enough? Seeking improvements in automotive component end-of-life. Resources, Conservation and Recycling, 2016. 110: p. 4860.

138. Hazen, B.T., D.A. Mollenkopf, and Y. Wang, Remanufacturing for the Circular Economy: An Examination of Consumer Switching Behavior. Business Strategy and the Environment, 2017. 26(4): p. 451-464.

139. Van Schaik, A. and M.A. Reuter, Recycling indices visualizing the performance of the circular economy. World of Metallurgy - ERZMETALL, 2016. 69(4): p. 201-216. 
140. Parajuly, K. and H. Wenzel, Product family approach in e-waste management: A conceptual framework for circular economy. Sustainability (Switzerland), 2017. 9(5).

141. Atlason, R.S., D. Giacalone, and K. Parajuly, Product design in the circular economy: Users' perception of endof-life scenarios for electrical and electronic appliances. Journal of Cleaner Production, 2017. 168: p. 10591069.

142. Ueberschaar, M., et al., Potentials and Barriers for Tantalum Recovery from Waste Electric and Electronic Equipment. Journal of Industrial Ecology, 2017. 21(3): p. 700-714.

143. Parajuly, K. and H. Wenzel, Potential for circular economy in household WEEE management. Journal of Cleaner Production, 2017. 151: p. 272-285.

144. Gaspari, L., et al., Modularization in material flow simulation for managing production releases in remanufacturing. Journal of Remanufacturing, 2017. 7(2-3): p. 139-157.

145. Botelho, A., et al., The market of electrical and electronic equipment waste in Portugal: Analysis of take-back consumers' decisions. Waste Management and Research, 2016. 34(10): p. 1074-1080.

146. Hartwell, I. and J. Marco, Management of intellectual property uncertainty in a remanufacturing strategy for automotive energy storage systems. Journal of Remanufacturing, 2016. 6(1).

147. Cong, L., F. Zhao, and J.W. Sutherland, Integration of dismantling operations into a value recovery plan for circular economy. Journal of Cleaner Production, 2017. 149: p. 378-386.

148. Jiménez-Rivero, A. and J. García-Navarro, Indicators to Measure the Management Performance of End-of-Life Gypsum: From Deconstruction to Production of Recycled Gypsum. Waste and Biomass Valorization, 2016. 7(4): p. 913-927.

149. Polzer, V.R., M.A.J. Pisani, and K.M. Persson, The importance of extended producer responsibility and the national policy of solid waste in Brazil. International Journal of Environment and Waste Management, 2016. 18(2): p. 101-119.

150. Jiang, Z., et al., A hybrid approach of rough set and case-based reasoning to remanufacturing process planning. Journal of Intelligent Manufacturing, 2016: p. 1-14.

151. Marlet, C., GtoG Life + Project: First step towards gypsum circular economy. ZKG International, 2014. 67(4): p. 48-55.

152. Gauffin, A., et al., The global societal steel scrap reserves and amounts of losses. Resources, 2016. 5(3).

153. Richter, J.L. and R. Koppejan, Extended producer responsibility for lamps in Nordic countries: Best practices and challenges in closing material loops. Journal of Cleaner Production, 2016. 123: p. 167-179.

154. Favot, M., R. Veit, and A. Massarutto, The evolution of the Italian EPR system for the management of household Waste Electrical and Electronic Equipment (WEEE). Technical and economic performance in the spotlight. Waste Management, 2016. 56: p. 431-437.

155. Jensen, J.P. and A. Remmen, Enabling Circular Economy Through Product Stewardship. Procedia Manufacturing, 2017. 8: p. 377-384.

156. Zhang, T., et al., Development pattern and enhancing system of automotive components remanufacturing industry in China. Resources, Conservation and Recycling, 2011. 55(6): p. 613-622. 
157. Tolio, T., et al., Design, management and control of demanufacturing and remanufacturing systems. CIRP Annals - Manufacturing Technology, 2017. 66(2): p. 585-609.

158. Niero, M. and S.I. Olsen, Circular economy: To be or not to be in a closed product loop? A Life Cycle Assessment of aluminium cans with inclusion of alloying elements. Resources, Conservation and Recycling, 2016. 114: $p$. 18-31.

159. Mo, H., Z. Wen, and J. Chen, China's recyclable resources recycling system and policy: A case study in Suzhou. Resources, Conservation and Recycling, 2009. 53(7): p. 409-419.

160. Wübbeke, J. and T. Heroth, Challenges and political solutions for steel recycling in China. Resources, Conservation and Recycling, 2014. 87: p. 1-7.

161. Jiménez-Rivero, A. and J. García-Navarro, Best practices for the management of end-of-life gypsum in a circular economy. Journal of Cleaner Production, 2017. 167: p. 1335-1344.

162. Zhang, J.H. and M. Chen, Assessing the impact of China's vehicle emission standards on diesel engine remanufacturing. Journal of Cleaner Production, 2015. 107: p. 177-184.

163. van Loon, P. and L.N. Van Wassenhove, Assessing the economic and environmental impact of remanufacturing: a decision support tool for OEM suppliers. International Journal of Production Research, 2017: p. 1-13.

164. Gumley, W., An analysis of regulatory strategies for recycling and re-use of metals in Australia. Resources, 2014. 3(2): p. 395-415.

165. Krystofik, M., et al., Adaptive remanufacturing for multiple lifecycles: A case study in office furniture. Resources, Conservation and Recycling, 2018. 135: p. 14-23.

166. Cherry, C.E. and N.F. Pidgeon, Why is ownership an issue? Exploring factors that determine public acceptance of product-service systems. Sustainability (Switzerland), 2018. 10(7).

167. Nasiri, M., et al., Transition towards sustainable solutions: Product, service, technology, and business model. Sustainability (Switzerland), 2018. 10(2).

168. Hobson, K., et al., Systems of practice and the Circular Economy: Transforming mobile phone product service systems. Environmental Innovation and Societal Transitions, 2018. 26: p. 147-157.

169. van Loon, P., C. Delagarde, and L.N. Van Wassenhove, The role of second-hand markets in circular business: a simple model for leasing versus selling consumer products. International Journal of Production Research, 2018. 56(1-2): p. 960-973.

170. Khan, M.A., et al., Review on upgradability - A product lifetime extension strategy in the context of product service systems. Journal of Cleaner Production, 2018. 204: p. 1154-1168.

171. Lüdeke-Freund, F., S. Gold, and N.M. Bocken, A Review and Typology of Circular Economy Business Model Patterns. Journal of Industrial Ecology, 2018.

172. Copani, G. and S. Behnam, Remanufacturing with upgrade PSS for new sustainable business models. CIRP Journal of Manufacturing Science and Technology, 2018.

173. Yang, M., et al., Product-service systems business models for circular supply chains. Production Planning and Control, 2018. 29(6): p. 498-508.

174. Kjaer, L.L., et al., Product/Service-Systems for a Circular Economy: The Route to Decoupling Economic Growth from Resource Consumption? Journal of Industrial Ecology, 2018. 
175. Perey, R., et al., The place of waste: Changing business value for the circular economy. Business Strategy and the Environment, 2018. 27(5): p. 631-642.

176. Wells, P. and P. Nieuwenhuis, Over the hill? Exploring the other side of the Rogers' innovation diffusion model from a consumer and business model perspective. Journal of Cleaner Production, 2018. 194: p. 444-451.

177. Levänen, J., T. Lyytinen, and S. Gatica, Modelling the Interplay Between Institutions and Circular Economy Business Models: A Case Study of Battery Recycling in Finland and Chile. Ecological Economics, 2018. 154: p. 373-382.

178. Chamberlin, L. and C. Boks, Marketing approaches for a circular economy: Using design frameworks to interpret online communications. Sustainability (Switzerland), 2018. 10(6).

179. Hopkinson, P., et al., Managing a Complex Global Circular Economy Business Model: Opportunities and Challenges. California Management Review, 2018. 60(3): p. 71-94.

180. Ünal, E., A. Urbinati, and D. Chiaroni, Managerial practices for designing circular economy business models: The case of an Italian SME in the office supply industry. Journal of Manufacturing Technology Management, 2018.

181. Sarasini, S. and M. Linder, Integrating a business model perspective into transition theory: The example of new mobility services. Environmental Innovation and Societal Transitions, 2018. 27: p. 16-31.

182. Appelgren, S., History as business: Changing dynamics of retailing in Gothenburg's second-hand market. Business History, 2018: p. 1-15.

183. Kjaer, L.L., et al., Guidelines for evaluating the environmental performance of Product/Service-Systems through life cycle assessment. Journal of Cleaner Production, 2018. 190: p. 666-678.

184. Chen, C.W., Guidance on the conceptual design of sustainable product-service systems. Sustainability (Switzerland), 2018. 10(7).

185. Núñez-Cacho, P., et al., Family businesses transitioning to a circular economy model: The case of "Mercadona". Sustainability (Switzerland), 2018. 10(2).

186. Sousa-Zomer, T.T., et al., Exploring the challenges for circular business implementation in manufacturing companies: An empirical investigation of a pay-per-use service provider. Resources, Conservation and Recycling, 2018. 135: p. 3-13.

187. Bocken, N.M.P., C.S.C. Schuit, and C. Kraaijenhagen, Experimenting with a circular business model: Lessons from eight cases. Environmental Innovation and Societal Transitions, 2018. 28: p. 79-95.

188. de Mattos, C.A. and T.L.M. de Albuquerque, Enabling factors and strategies for the transition toward a circular economy (CE). Sustainability (Switzerland), 2018. 10(12).

189. Veleva, V. and G. Bodkin, Emerging drivers and business models for equipment reuse and remanufacturing in the US: lessons from the biotech industry. Journal of Environmental Planning and Management, 2018. 61(9): p. 1631-1653.

190. Dentchev, N., et al., Embracing the variety of sustainable business models: $A$ prolific field of research and a future research agenda. Journal of Cleaner Production, 2018. 194: p. 695-703.

191. Poppelaars, F., C. Bakker, and J. van Engelen, Does access trump ownership? Exploring consumer acceptance of access-based consumption in the case of smartphones. Sustainability (Switzerland), 2018. 10(7). 
192. Manninen, K., et al., Do circular economy business models capture intended environmental value propositions? Journal of Cleaner Production, 2018. 171: p. 413-422.

193. Heyes, G., et al., Developing and implementing circular economy business models in service-oriented technology companies. Journal of Cleaner Production, 2018. 177: p. 621-632.

194. Wastling, T., F. Charnley, and M. Moreno, Design for circular behaviour: Considering users in a circular economy. Sustainability (Switzerland), 2018. 10(6).

195. Lahti, T., J. Wincent, and V. Parida, A definition and theoretical review of the circular economy, value creation, and sustainable business models: Where are we now and where should research move in the future? Sustainability (Switzerland), 2018. 10(8).

196. Stål, H.I. and H. Corvellec, A decoupling perspective on circular business model implementation: Illustrations from Swedish apparel. Journal of Cleaner Production, 2018. 171: p. 630-643.

197. Ranta, V., L. Aarikka-Stenroos, and S.J. Mäkinen, Creating value in the circular economy: A structured multiplecase analysis of business models. Journal of Cleaner Production, 2018. 201: p. 988-1000.

198. Veleva, V. and G. Bodkin, Corporate-entrepreneur collaborations to advance a circular economy. Journal of Cleaner Production, 2018. 188: p. 20-37.

199. Sinclair, M., et al., Consumer intervention mapping-A tool for designing future product strategies within circular product service systems. Sustainability (Switzerland), 2018. 10(6).

200. Lieder, M., et al., A conjoint analysis of circular economy value propositions for consumers: Using "washing machines in Stockholm" as a case study. Journal of Cleaner Production, 2018. 172: p. 264-273.

201. Singh, P. and E. Giacosa, Cognitive biases of consumers as barriers in transition towards circular economy. Management Decision, 2018.

202. Goyal, S., M. Esposito, and A. Kapoor, Circular economy business models in developing economies: Lessons from India on reduce, recycle, and reuse paradigms. Thunderbird International Business Review, 2018. 60(5): p. 729-740.

203. Zucchella, A. and P. Previtali, Circular business models for sustainable development: A "waste is food" restorative ecosystem. Business Strategy and the Environment, 2018.

204. Frishammar, J. and V. Parida, Circular Business Model Transformation: A Roadmap for Incumbent Firms. California Management Review, 2018.

205. Nußholz, J.L.K., A circular business model mapping tool for creating value from prolonged product lifetime and closed material loops. Journal of Cleaner Production, 2018. 197: p. 185-194.

206. Oghazi, P. and R. Mostaghel, Circular business model challenges and lessons learned-An industrial perspective. Sustainability (Switzerland), 2018. 10(3).

207. Geissdoerfer, M., et al., Business models and supply chains for the circular economy. Journal of Cleaner Production, 2018. 190: p. 712-721.

208. Aboulamer, A., Adopting a circular business model improves market equity value. Thunderbird International Business Review, 2018. 60(5): p. 765-769.

209. Zink, T., R. Geyer, and R. Startz, Toward Estimating Displaced Primary Production from Recycling: A Case Study of U.S. Aluminum. Journal of Industrial Ecology, 2018. 22(2): p. 314-326. 
210. Kunz, N., K. Mayers, and L.N. Van Wassenhove, Stakeholder Views on Extended Producer Responsibility and the Circular Economy. California Management Review, 2018. 60(3): p. 45-70.

211. Coughlan, D., C. Fitzpatrick, and M. McMahon, Repurposing end of life notebook computers from consumer WEEE as thin client computers - A hybrid end of life strategy for the Circular Economy in electronics. Journal of Cleaner Production, 2018. 192: p. 809-820.

212. Tran, H.P., et al., Recycling portable alkaline/ZnC batteries for a circular economy: An assessment of natural resource consumption from a life cycle and criticality perspective. Resources, Conservation and Recycling, 2018. 135: p. 265-278.

213. Brouwer, M.T., et al., Predictive model for the Dutch post-consumer plastic packaging recycling system and implications for the circular economy. Waste Management, 2018. 71: p. 62-85.

214. Hahladakis, J.N., et al., Post-consumer plastic packaging waste in England: Assessing the yield of multiple collection-recycling schemes. Waste Management, 2018. 75: p. 149-159.

215. Tsiliyannis, C.A., Markov chain modeling and forecasting of product returns in remanufacturing based on stock mean-age. European Journal of Operational Research, 2018. 271(2): p. 474-489.

216. Low, J.S.C. and Y.T. Ng, Improving the Economic Performance of Remanufacturing Systems through Flexible Design Strategies: A Case Study Based on Remanufacturing Laptop Computers for the Cambodian Market. Business Strategy and the Environment, 2018. 27(4): p. 503-527.

217. Wang, P. and A.T.H. Kuah, Green marketing cradle-to-cradle: Remanufactured products in Asian markets. Thunderbird International Business Review, 2018. 60(5): p. 783-795.

218. Bag, S., S. Gupta, and C. Foropon, Examining the role of dynamic remanufacturing capability on supply chain resilience in circular economy. Management Decision, 2018.

219. Liu, B., et al., The effect of remanufacturing and direct reuse on resource productivity of China's automotive production. Journal of Cleaner Production, 2018. 194: p. 309-317.

220. Rentizelas, A., A. Shpakova, and O. Mašek, Designing an optimised supply network for sustainable conversion of waste agricultural plastics into higher value products. Journal of Cleaner Production, 2018. 189: p. 683-700.

221. Sabbaghi, M. and S. Behdad, Consumer decisions to repair mobile phones and manufacturer pricing policies: The concept of value leakage. Resources, Conservation and Recycling, 2018. 133: p. 101-111.

222. Marconi, M., et al., Applying data mining technique to disassembly sequence planning: a method to assess effective disassembly time of industrial products. International Journal of Production Research, 2018: p. 1-25.

223. Mishra, J.L., P.G. Hopkinson, and G. Tidridge, Value creation from circular economy-led closed loop supply chains: a case study of fast-moving consumer goods. Production Planning and Control, 2018. 29(6): p. 509521.

224. Masi, D., et al., Towards a more circular economy: exploring the awareness, practices, and barriers from a focal firm perspective. Production Planning and Control, 2018. 29(6): p. 539-550.

225. Govindan, K. and M. Hasanagic, A systematic review on drivers, barriers, and practices towards circular economy: a supply chain perspective. International Journal of Production Research, 2018: p. 1-34.

226. De Angelis, R., M. Howard, and J. Miemczyk, Supply chain management and the circular economy: towards the circular supply chain. Production Planning and Control, 2018. 29(6): p. 425-437. 
227. Dubey, R., et al., Supplier relationship management for circular economy: Influence of external pressures and top management commitment. Management Decision, 2018.

228. Jain, S., N.K. Jain, and B. Metri, Strategic framework towards measuring a circular supply chain management. Benchmarking, 2018. 25(8): p. 3238-3252.

229. Habibi, M.K.K., et al., Sample average approximation for multi-vehicle collection-disassembly problem under uncertainty. International Journal of Production Research, 2018.

230. Howard, M., P. Hopkinson, and J. Miemczyk, The regenerative supply chain: a framework for developing circular economy indicators. International Journal of Production Research, 2018.

231. Kazancoglu, Y., I. Kazancoglu, and M. Sagnak, A new holistic conceptual framework for green supply chain management performance assessment based on circular economy. Journal of Cleaner Production, 2018. 195: p. 1282-1299.

232. Yılmaz Balaman, Ş., et al., Network design and technology management for waste to energy production: An integrated optimization framework under the principles of circular economy. Energy, 2018. 143: p. 911-933.

233. Laso, J., et al., Introducing the Green Protein Footprint method as an understandable measure of the environmental cost of anchovy consumption. Science of the Total Environment, 2018. 621: p. 40-53.

234. Batista, L., et al., In search of a circular supply chain archetype-a content-analysis-based literature review. Production Planning and Control, 2018. 29(6): p. 438-451.

235. Lapko, Y., et al., In Pursuit of Closed-Loop Supply Chains for Critical Materials: An Exploratory Study in the Green Energy Sector. Journal of Industrial Ecology, 2018.

236. Lin, Y., et al., An improved artificial bee colony for facility location allocation problem of end-of-life vehicles recovery network. Journal of Cleaner Production, 2018. 205: p. 134-144.

237. Larsen, S.B., et al., How the reverse supply chain contributes to a firm's competitive strategy: a strategic alignment perspective. Production Planning and Control, 2018. 29(6): p. 452-463.

238. Liu, J., et al., Green supply chain management and the circular economy: Reviewing theory for advancement of both fields. International Journal of Physical Distribution and Logistics Management, 2018. 48(8): p. 794817.

239. Ghisellini, P., M. Ripa, and S. Ulgiati, Exploring environmental and economic costs and benefits of a circular economy approach to the construction and demolition sector. A literature review. Journal of Cleaner Production, 2018. 178: p. 618-643.

240. Botezat, E.A., et al., An exploration of circular economy practices and performance among Romanian producers. Sustainability (Switzerland), 2018. 10(9).

241. Brown, P.J. and C. Bajada, An economic model of circular supply network dynamics: Toward an understanding of performance measurement in the context of multiple stakeholders. Business Strategy and the Environment, 2018. 27(5): p. 643-655.

242. Vlajic, J.V., R. Mijailovic, and M. Bogdanova, Creating loops with value recovery: empirical study of fresh food supply chains. Production Planning and Control, 2018. 29(6): p. 522-538.

243. Hahladakis, J.N. and E. lacovidou, Closing the loop on plastic packaging materials: What is quality and how does it affect their circularity? Science of the Total Environment, 2018. 630: p. 1394-1400. 
244. Batista, L., et al., Circular supply chains in emerging economies-a comparative study of packaging recovery ecosystems in China and Brazil. International Journal of Production Research, 2018.

245. Tsolakis, N., M. Kumar, and W. Bam, Circular supply chains and renewable chemical feedstocks: a network configuration analysis framework. Production Planning \& Control, 2018. 29(6): p. 464-482.

246. Leising, E., J. Quist, and N. Bocken, Circular Economy in the building sector: Three cases and a collaboration tool. Journal of Cleaner Production, 2018. 176: p. 976-989.

247. Stewart, R. and M. Niero, Circular economy in corporate sustainability strategies: A review of corporate sustainability reports in the fast-moving consumer goods sector. Business Strategy and the Environment, 2018. 27(7): p. 1005-1022.

248. Bressanelli, G., M. Perona, and N. Saccani, Challenges in supply chain redesign for the Circular Economy: a literature review and a multiple case study. International Journal of Production Research, 2018.

249. Braun, A.T., et al., Case study analysing potentials to improve material efficiency in manufacturing supply chains, considering circular economy aspects. Sustainability (Switzerland), 2018. 10(3).

250. Braz, A.C., et al., The bullwhip effect in closed-loop supply chains: A systematic literature review. Journal of Cleaner Production, 2018. 202: p. 376-389.

251. Mangla, S.K., et al., Barriers to effective circular supply chain management in a developing country context. Production Planning and Control, 2018. 29(6): p. 551-569.

252. Faussone, G.C., Transportation fuel from plastic: Two cases of study. Waste Management, 2018. 73: p. 416423.

253. Nowakowski, P. and B. Mrówczyńska, Towards sustainable WEEE collection and transportation methods in circular economy - Comparative study for rural and urban settlements. Resources, Conservation and Recycling, 2018. 135: p. 93-107.

254. Kourmentza, C., et al., Spent coffee grounds make much more than waste: Exploring recent advances and future exploitation strategies for the valorization of an emerging food waste stream. Journal of Cleaner Production, 2018. 172: p. 980-992.

255. Cobo, S., A. Dominguez-Ramos, and A. Irabien, From linear to circular integrated waste management systems: a review of methodological approaches. Resources, Conservation and Recycling, 2018. 135: p. 279-295.

256. Milios, L., et al., Plastic recycling in the Nordics: A value chain market analysis. Waste Management, 2018. 76 : p. 180-189.

257. Maßß, O. and P. Grundmann, Governing transactions and interdependences between linked value chains in a circular economy: The case of wastewater reuse in Braunschweig (Germany). Sustainability (Switzerland), 2018. 10(4).

258. Laso, J., et al., Finding an economic and environmental balance in value chains based on circular economy thinking: An eco-efficiency methodology applied to the fish canning industry. Resources, Conservation and Recycling, 2018. 133: p. 428-437.

259. Ranta, V., et al., Exploring institutional drivers and barriers of the circular economy: A cross-regional comparison of China, the US, and Europe. Resources, Conservation and Recycling, 2018. 135: p. 70-82. 
260. Lokesh, K., L. Ladu, and L. Summerton, Bridging the gaps for a 'circular' bioeconomy: Selection criteria, biobased value chain and stakeholder mapping. Sustainability (Switzerland), 2018. 10(6).

261. Huybrechts, D., et al., Best available techniques and the value chain perspective. Journal of Cleaner Production, 2018. 174: p. 847-856. 